UNITED STATES DEPARTMENT OF THE INTERIOR

Harold L. Ickes, Secretary

II.S GEOLOGICAL SURVEY

W. C. Mendenhall, Director

\title{
Bulletin 932
}

\section{GEOPHYSICAL ABSTRACTS}

\section{4-107}

\section{JANUARY-DECEMBER 1941}

\author{
COMPILED BY
}

W. AYVAZOGLOU

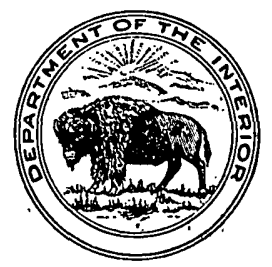

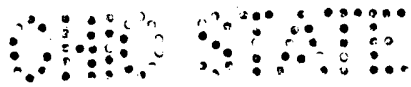

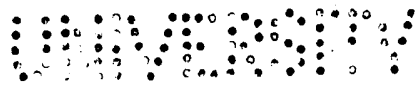

UNITED STATES

GOVERNMENT PRINTING OFFICE

WASHINGTON : 1942 


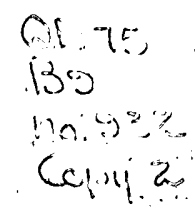

\section{CONTENTS}

The letters in parentheses are those used to designate the chapters for separate publication

(A) Geophysical Abstracts 104, January-March 1941 (Nos. 5877-5992) .-

(B) Geophysical Abstracts 105, April-June 1941 (Nos. 5993-6126) ...... -

(C) Geophysical Abstracts 106, July-September 1941 (Nos. 6127-6248) - -

(D) Geophysical Abstracts 107, October-December 1941 (Nos. 62496376)

Index, January -December 1941

Note.-Geophysical Abstracts 1-86 were issued in mimeographed form by the Bureau of Mines; Abstracts 87-103 were published in bulletins of the Geological Survey.

II

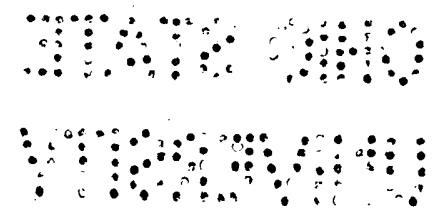


UNITED STATES DEPARTMENT OF THE INTERIOR

Harold L. Ickes, Secretary

GEOLOGICAL SURVEY

W. C. Mendenhall, Director

Bulletin 932-A

GEOPHYSICAL ABSTRACTS 104

JANUARY-MARCH 1941

COMPILED BY

W. AYVAZOGLOU

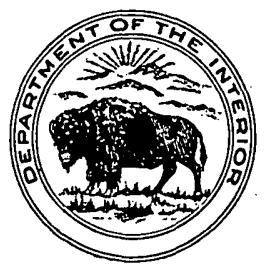

UNITED STATES

GOVERNMENT PRINTING OFFICE

WASHINGTON : 1941

For sale by the Superintendent of Documents, Washington, D. C. - - - - - Price 10 cents

\section{8}




\section{CONTENTS}

1. Gravitational methods.

2. Magnetic methods ....... 5

3. Seismic methods

4. Electrical methods . . .

5. Radioactive methods............ 23

6. Geothermal methods . .

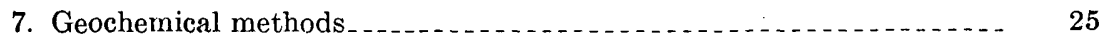

8. Unclassified methods and topics related to geophysics_........ 25

9. New publications. ...

10. Patents

Index

NотE.-Geophysical Abstracts 1-86 were issued in mimeographed form by the Bureau of Mines; Abstracts 87-103 were published in bulletins of the Geological Survey.

II 


\section{GEOPHYSICAL ABSTRACTS 104, JANUARY-MARCH 194]}

\section{Compiled by W. Arvazoglou}

\section{GRAVITA'TIONAL METHODS}

5877. Abelski, M. E., Application of rigid threads for more rapid work with variometers [in Russian]: Razvedka Nedr, vol. 10, No. 7, pp. 38-41, Moscow, 1940.

The writer proposes the use of rigid threads, to which the beam of a variometer is suspended, to shorten the time of observations in making surveys where high accuracy of measurements is not: required, as in recomnaissance surveys or in large anomalies of gravitational fields. He discusses theoretical reasons, data of calculation, and laboratory and field tests to prove the utility of the proposed method.- $-W . A$.

5878. Ballarin, S., Eötvösian elements: Ricerca sci.; vol. 11, No. 1, pp. 7-82, and No. 2, pp. 139-158, Rome, 1940.

A new network for calculating the Eötvösian elements of infinite, homogeneous cylinders is described. It is useful for the interpretation of gravimetric projections executed with the torsion balance. The second paper determines the approximate correction to the second derivative of the calculated potential for an infinite cylinder.-W. A. R., Sci. Abstracts, vol. 43, No. 512, 1940.

5879. Gnass, Gerhard, Bestimmung gezeitlicher Änderungen des Schwerevektors hinsichtlich der Tide $\mathrm{M}_{2}$ aus gleichżeitigen Horizontalpendelbeobachtungen in Pillnitz, Berchtesgaden, und Beuthen [Determination of tidal changes of the gravity vector with regard to the tide $\mathbf{M}_{2}$ from simultaneous horizontal-pendulum observations in Pillnitz, Berchtesgaden, and Beuthen] : Zeitschr. Geophysik, vol. 16, No. 1/2, :pp. 1-15, Brunswick, 1940.

This article is related to one by Schaffernicht entitled "Horizontalpendulum observations on the changes of plumb lines at Marburg" (see Geophys. Abstracts 91, No. 3944). The writer measured simultaneously derivations of plumb lines at Pillnitz. Berchtesgaden, and Beuthen to obtain information on the regional relations of the differences of values in the deviations of the plumb line. In addition, he determined the secular change of gravity acceleration for all three directions of the coordinates $X, Y, Z$ from the plumb-line deviations, together with the values for the variation of the vertical intensity of gravity. He describes both the apparatus and the method of measurements, evaluates the curves that are recorded in tables, and presents the results of his observations in a series of curves that show 
the theoretical and observed plumb-line deviations for the $M_{2}$ member (main-moon member) at the three places investigated.-W.A.

5880. Graf, Anton, Stellungnahme zur vorstehenden Abhandlung von G. Ising über die Bestimmung der Apparatkonstante bei astasierten Gravimetern [Reply to G. Ising's article on the determination of the constants of the apparatus in astatized gravimeters]: Zeitschr. Geophysik, vol. 16, No. 1/2, pp. 31-33, Brunswick, 1940 .

Graf, in this article, answers Ising's criticism of the former's article "On the determination of the gravimeter constant in a freely suspended spring-system" (see abstract. 5883). Graf states that he intended not to prove that astatized gravimeters are less accurate than nonastatized ones but to prove that laboratory determinations of scale values in a freely suspended spring-system are easy and simple, for the measurement formula is very clearly shown on the instrument. Besides; the most simple and accurate methods of measurement used in practical physics can be applied.-W. $A$.

5881. Hendricks, T. A., Structural interpretation of recent gravity observations in southeastern Oklahoma: Am. Assoc. Petroleum Geologists Bull., vol. 24, No. 12, pp. 2143-2149, Tulsa, Okla., 1940.

Fourteen new gravity determinations have been made by the United States Coast and Geodetic Survey on and near the north border of the Coastal Plain in southeastern Oklahoma. The stations are located near township corners and form a grid surrounding the junction of the Ouachita and Arbuckle mountain systems beneath Cretaceous strata of the Coastal Plain. Gravity anomalies computed by the Coast and Geodetic Survey show a broad nose of high positive anomalies that coincides with the granite core of the Tishomingo anticline of the Arbuckle Mountains and with its southeastward prolongation beneath the Coastal Plain. The nose extends southeastward at least 12 miles deep in the northwest front of the Ouachita Mountain structural province between Atoka, Okla., and Denison, Tex.-Author's abstract.

5882. Hoffman, M. G., Structural history of Billings field, Noble County, Okla., interpreted in terms of isostasy : Am. Assoc. Petroleum Geologists Bull., vol. 24, No. 11, pp. 2006-2018, Tulsa, Okla., 1940.

"This paper is an attempt to apply the theory of isostasy in the interpretation of the geologic events of the Billings dome, Noble County, Okla. This dome is believed to have been thrust upward periodically from Cambrian time to early Pennsylvanian time. Each period of upthrusting appears to have been directly related to the deposition of thick bodies of sediment in southern Oklahoma. The greatest deformation, during which the Billings anticline was folded and faulted, followed the deposition of the Mississippian limestone. This deformation occurred while 20,000 feet of sediments were accumulating in the Ouachita basin and 6,000 feet of sediments were accumulating in the ArdmoreAnadarko basin. During most of Pennsylvanian and Permian time more than 4,000 feet of sediments were deposited in the region including the Billings dome. Differential downward adjustment of the earth's crust was necessary to compensate for this overload of sediments. The downward adjustment was greater in the synclines adjacent to the dome than on it, which made it possible for the Billings fold to be reflected upward through the beds to the surface.-Author's abstract. 
5883. Ising, Gustaf, Die Bestimmung der Apparatkonstanten bei astasierten Gravimetern [Determination of the constants of the apparatus in astatized gravimeters]: Zeitschr. Geophysik, vol. 16, No. 1/2, pp. 27-30, Brunswick, 1940.

This is a comment on Graf's article "On the determination of the gravimeter constant in a freely suspended spring-system" (see Geophys. Abstracts 97, No. 4888; for Graf's answer to Ising's criticism, see abstract 5880). Ising rejects as erroneous Graf's statement that laboratory calibration of astatized gravimeters can be made with only a very limited accuracy, owing to the principles involved, and he cites as experimental evidence of the accuracy of the calibration (about 0.5 percent) of a gravimeter with an astatized, almost vertical pendulum the results of measurements made in $\mathbf{1 9 3 8}$ with two gravimeters between Stockholm and Copenhagen.-Author's abstract, translated by W. A.

5884. Kedves, M., Gravitationsuntersuchungen mit einer neuen Torsionswaage [Gravitational investigations with a new torsion balance]: Acta chem., min. et phys., vol. 7, F 2, pp. 64-92, Szeged, 1939.

For 10 years after the death of Baron von Eötvös, the author continued his experimental work of improving the ordinary torsion balance. In its present form the instrument consists of a light horizontal beam with two small weights at its ends (each about $10 \mathrm{~g}$.). The beam is suspended by a torsion thread $470-480 \mathrm{~mm}$. in length and $0.04 \mathrm{~mm}$. in diameter, and is made of a platinum-iridium alloy. Mutual attraction of solid and liquid bodies can be shown (proportionately between gravitation and mass); the constant of gravitation and the change of the horizontal component of gravity can be determined. The author gives the theory concerning the instrument, discusses several experiments, and presents detailed records of observation. Static performance of the experiments is possible. One disadvantage of the instrument is the length of time necessary for its adjustment (from $1 \mathrm{hr}$. to several hours). He determined the accuracy of the instrument by examining the values obtained for the constant of gravity. He shows that the mean error in these values is about \pm 10 percent. A stable mounting is required for obtaining precise measurements. Several instruments should be used for checking the results.-Lettau's abstract in Gerlands Beitr. Geophysil, vol. 56, No. 4, 1940, translated by W. A.

5885. Lukavchenko, P. I., and Sajina, N. B., Ising's quartz gravimeter and results of observations made with it in the Ivanovsk region [in Russian]: Razvedka Nedr, vol. 10, No. 9, pp. 37-46, Moscow, 1940.

The authors give information about the theory and construction of Ising's quartz gravimeter and compare its advantages in making gravimetrical surveys with those of pendulums and variometers. They mention especially its efficiency, which is $\mathbf{5}$ to $\mathbf{1 0}$ times higher than that of pendulum instruments. They give results of a survey made with Ising's gravimeter in the Ivanovsk region along a profile $60 \mathrm{~km}$. long. Distances between the points of observation were about $3 \mathrm{~km}$., but at some places they were reduced to $1.5 \mathrm{~km}$. They made 22 observations during the 15 days of work. The mean error of one observation was equal to \pm 0.9 milligal. They applied free-air and Bouguer reductions to the gravity anomalies, the values of which they show in diagrams. The 
regional change in gravity is supposed to be related to the crystalline basement of the given area; therefore the curves of the anomalies of gravity may represent the form of the top of the pre-Cambrian crystalline massif.-W. $A$.

5886. Miller, A. H., Gravity determinations in 1937 and 1938: Dominion Observatory, vol. 11, No. 5, pp. 145-171, Ottawa, 1940.

Gravity anomalies corresponding to several methods of reduction are given for 25. stations recently established in eastern Canada and Newfoundland. Most of the large anomaly stations are in pre-Cambrian areas where the more pronounced are in every case negative. A map, showing results for some 150 gravity stations so far established in Canada, accompanies the report.-Author's abstract.

5887. Miller, A. H., Investigations of gravitational and magnetometric methods of geophysical prospecting: Dominion Observatory, Dept. Mines and Resources, Ottawa, 1940.

The author gives a thoroughly illustrated report on investigations with the torsion balance and magnetometer. He describes several typical and important geologic structures that have been investigated, and he mentions problems actually or potentially of great practical im. portance., The apparent value of the methods varied greatly from one problem to another. In some problems the methods appeared to have little or no application; in others they appeared to be very useful. There are many problems in Canada in which the methods could be successfully applied, especially when allowance is made for future development of the methods.-From abstract in Canadian, Min. Jour., vol. 61, No. 11, 1940, condensed by W. A.

5888. Voit, H., Über die Erzielung möglichst grosser innerer ind absoluter Genauigkeit bei der Analyse von Horizontalpendel und Gravimeterbeobachtungen [On the acquirement of the highest relative and absolute accuracy in analyzing observations made with horizontal pendulums and gravimeters]: Zeitschr. Geophysik, vol. 16, No. 1/2, pp. 16-26, Brunswick, 1940.

Measurements of the deformation of the solid earth caused by tidal forces may provide information on the elastic behavior of the earth and probably also on the structure of the earth's crust. A most accurate interpretation of the observations is required. The mathematical discussion, accompanied by tables and graphs, is based on previous work on this subject by Tomaschek, Schaffernicht, Gnass, and others.- $W$. $A$.

5889. Wegener, Kurt, Die hydrostatische Reduktion der Schwerebeobachtungen [The hydrostatic reduction of gravity observations]: Zeitschr. Geophysik, vol. 16, No. 1/2, pp. 33-39, Brunswick, 1940.

The writer compares the hydrostatic reduction of gravity observations with the methods of reduction usually applied, such as the freeair, Bouguer's, and Prey's reduction. He discusses the principle of hydrostatic reduction and graphically represents the different reductions. $-W . A$. 
5890. Wolf, : Alfred, Tidal-force observations: Geophysics, vol, 5, No. 4, pp. 317-320, Menasha, Wis., 1940.

Observations of the tidal variation of gravity at Tulsa, Okla., are presented for the period December 10 to December 16, 1989. A good correlation is found between observed and calculated values with the factor $(1+\mathrm{h}-3 \mathrm{k} / 2)=1.2$. Author's abstract.

\section{MAGNETIC METHODS}

5891. Benkova, N. P., Spherical harmonic analysis of the $S_{q}$ variations, MayAugust 1933: Terres. Magn. and Atmos. Electr., vol. 35, No. 4, pp. 425-432, Baltimore, Md., 1940.

The writer gives the results of a spherical harmonic analysis of the quiet solar diurnal variations $S_{q}$ in the earth's magnetic field from May to August 1933. The spherical harmonic analysis of the earth's permanent and transient magnetic fields is of the utmost importance because, first, it permits generalizing the empirical data in the form of an analytical expression and, second, it offers information regarding the structure of this field (its potential and its origin). With the accumulation of new observations it becomes desirable to have recourse, from time to time, to new analyses. The writer also discusses the normal diurnal variations of the three components of the earth's magnetic field, as recorded at 46 stations during this same period.-W. $A$.

5892. Chapman, S., Notes on isomagnetic charts, Part 1., Their singular points and contour lines: Terres. Magn. and Atmos. Electr., vol. 45, No. 4, pp. 433-442, Baltimore, Md., 1940.

Some aspects of the geometry of isomagnetic charts (using isomagnetic in a wide sense) are considered, particularly as regards their ray poles and singular points-foci and nodes. Special types of singular points are shown to include circular foci, rectangular nodes, and cusps. Some suggestions are made regarding the construction of isomagnetic charts.-Author's abstract.

5893. Chapman, S., Notes on isomagnetic charts, Part 2, The form and disposition of the nodal curves: Terres. Magn. and Atmos. Electr., vol. 45, No. 4, pp. 443-450, Baltimore, Md., 1940.

The form of the special isomagnetic lines which cross themselves (the nodal curves) is discussed, and the nature of the regions into which they divide the surface of the sphere. Geomagnetic illustrations of the simpler types of isomagnetic chart are cited.-Author's abstract.

5894. Fleming, J. A., Geomagnetism and its geologic significance: Internat. Geod. and Geophys. Union, 7th Gen. Assembly, Document A, pp. 55-57, Washington, D. C., September 1939.

A general discussion on the subject, with particular reference to magnetic features of the oceanic basins. It is brought out that with improved knowledge of magnetic anomalies, their interrelations to gravity anomalies and deep-focus earthquakes may be studied. Numerous phases of this broad subject, such as magnetic measurements on ocean-bottom cores, secular variation as related to regional geologic structure, and the like are considered.-D. W., Mines Mag., vol. 30, No. 11, 1940. 
5895. Hallimond, A. F., and Butler, A. J., Magnetic survey over faults near Hale, West Cumberland: Great Britain Geol. Survey, Dept. Sci. and Ind. Research, Wartime pamphlet 3, 6 pp., South Kensington, Jụne 1940:

A detailed magnetic survey has been made over faults near the margin of the outcrop of the Borrowdale Volcanic Series at Hale, near Beckermet, West Cumberland. The observed magnetic profiles are shown to agree with those calculated for the geological structure deduced by Dr. F. M. Trotter (with minor adjustments); the position of several faults has been ascertained, and a revised map of the area has been made. Traverses over the main ore field near Hale and Beckermet indicate that no measurable magnetic anomaly is associated with faults, where these affect the weakly magnetic formations of the district under a cover of over 1,000 feet. Another point to be noted is that the values for $K_{v}$ assigned to the Brockram $\left(25 \times 10^{-6}\right)$ and Borrowdale rocks $\left(75 \times 10^{-5}\right)$ are such as to render the detection of an anomaly due to iron ore at depth almost impossible where these rocks are present.-Authors' abstract.

5896. Jones, W. M., Variations of vertical magnetic intensity at Rotorua, and their relation to the thermal activity: New Zealand Jour. Sci. Technology, General Section, vol. 21, No. 6b, pp. 289b-296b, Wellington, 1940.

Variations of 600 gammas in vertical magnetic intensity were found in the environs of Rotorua, the maximum positive disturbance being in the vicinity of Pukeroa Hill. The rhyolite exposed at Kawaha Point produced anomalies of the order of 2,000 gammas and could be traced below the surface for about a mile in the direction of Rotorua, and likewise the rhyolite cropping out on the southeast margin of Lake Rotorua appears to continue below the surface nearly as far as the mouth of the Puarenga stream. Blocks of a similar rhyolite were seen in a cut on the east side of Pukeroa Hill, and the magnetic disturbance here is considered to be due to a body of such rhyolite just reaching the surface. The areas of thermal activity were found to follow the zones of low intensity surrounding the positive disturbances; and it is suggested that the flanks of the rhyolite body are not yet entirely cool and are thus responsible for the thermal activity. The possibility is discussed of a similar origin for the thermal activity at Whakarewarewa and elsewhere--Author's abstract.

5897. Jordan, W. H., A magnetic survey of central South Dakota: South Dakota Geol. Survey, Rept. of Inv., No. 37, 35 pp., Vermillion, 1940.

The work described in this report is part of a large program to make a magnetic survey of the entire State of South Dakota. Begun in the summer of 1939, the work was described in a previous paper (see Geophys. Abstracts 101, No. 5474). The area surveyed at that time included most or all of Aurora, Brule, Davison, and Douglas Counties and a large part of Buffalo, Charles Mix, and Hand Counties. One hundred and eighteen magnetometer stations were set. Surveys this year were extended to areas of interest to the major oil companies, as shown on the index map. These areas, covering about 10,000 square miles, include all of Buffalo, Campbell, Faulk, Hand, Hughes, Hyde, 
Potter, Sully, and Walworth Counties. The author discusses the procedure, results, method of interpretation of magnetic data, and possible causes of magnetic variations. $-W$. $A$.

5898. Kato, Yosio, Investigation of the changes in the earth's magnetic field accompanying earthquakes or volcanic eruptions, Part 2 , On the strong earthquake of May 29, 1938, which occurred near Kuttyaro Lake, Hokkaido: Sci. Repts. of the Tohoku Imp. Univ., vol. 29, No. 3, pp. 315328 , Sendai, 1940.

This is a description of topographic changes, the phenomenon of tunami, luminous effects, the damage of houses, changes of amount of radium emanation, the disturbance of the vertical intensity of the magnetic field at the epicentral area, and time variations of the magnetic anomaly. The writer measured the vertical intensity of the earth's magnetic field with a Schmidt field balance after the earthquake and found an intimate relation between the magnetic disturbance and the seismic activity of this earthquake. The amount of the magnetic anomaly reached more than 100 gammas. The anomaly decreased in amount but did not revert to the original value during an interval of 1 year after the earthquake. The writer observed a remarkable change in the amount of radium emanation of hot springs at Tesikaga after the earthquake. The value observed in 1.936 was 13.9 mache, whereas in June 1939 it was 6.9 mache.-W. A.

5899. Kato, Yosio, Investigation of the changes in the earth's magnetic field accompanying earthquakes or volcanic eruptions, Part 3 , On the strong earthquake of November 5,1938 , which occurred in the sea bottom near Iwaki, Fukusima Prefecture: Sci. Repts. of the Tohoku Imp. Univ., vol. 29, No. 3, pp. 329-342, Sendai, 1940.

Two remarkable phenomena were observed during the earthquake that occurred on the sea bottom near Iwaki. (1) The damage caused by this earthquake was limited to the region between Namie and Sinzan, which are about 5 miles apart. The localized damage is considered to be due to movement of a single block of the earth's crust. The observed values of the local disturbance of the vertical intensity of the earth's magnetic field are shown in a diagram. (2) A tumami was associated not only with the first earthquake but also with the relatively great earthquake that followed. This fact illustrates that the crustal movement must have occurred on the bottom of the sea near the epicenter and that the crustal movement was not completed during the first earthquake but continued through the following earthquake. This is a remarkable phenomenon because a tunami is generally considered to accompany only the first earthquake. $-W . A$.

5900. Lyddne, R. H., and Ruark, A., Coils for the production of a uniform magnetic field: Rev. Sci. Instruments, vol. 10, No. 9, pp. 253-257, Lancaster, Pa., September 1939.

The writers discuss the production of a highly uniform magnetic fleld in a rectangular box, which is long compared to its cross section, by means of a pair of rectangular coils on the ends of the box. The mathematics of the case presented is developed. It was found that a flald comparing favorably in uniformity with that from Felmholtz coils was produced.-D. W., Mines Mag., vol. 30, No. 11, 1940 .

$407408-41-2$ 
5901. Lynton, E. D., The mechanics of the upside-down core: Geophysics, vol. 5, No. 4, pp. 393-401, Menasha, Wis., 1540.

Very frequently cores taken from trays and oriented by the HerrickLynton method of magnetic-core orientation have been wrongly marked as to top and bottom. If the bottom of the core is run as top, the resulting orientation is not $180^{\circ}$ off unless the points of the compass are marked similarly to a Brunton compass, namely, transposition of east and west.--Author's abstract.

5902. Marquardt, C. M., Magnetic prospecting in metal mining: Mining Jour., vol. 23, No. 4, pp. 3-4, Phoenix, Ariz., 1939.

A soundly based discussion of the applicability of magnetic surveys to mining problems with the background idea that such work offers a method of securing additional data upon which to base deductions regarding structural and hence economic geology. Examples are cited from the iron regions of Michigan, Wisconsin, and Minnesota, from surveys in connection with bauxite in Arkansas and the mapping of a rhyolite dike in Arizona. It is brought out that magnetic methods might save much money in the exploration of prospects. The author writes from a background of practical experience.-D. W., Mines Mag., vol 30, No. 11, 1940.

5903. Milstein, M., The place of magnetometry in geophysics-Depth determinations and abnormal polarity: Ind. Australian and Mining Standard, vol. 95, No. 2461, pp. 317-319, Melbourne, December 1, 1940.

The writer has developed new formulas for determining the nature and depth of various anomaly-producing layers, which may embrace three, four, or sometimes more lithologically definable discontinuities within one vertical column. The formulas are equally applicable to the shallowest or deepest responsive strata and do not depend on the size of anomaly. The interpretative technique provides a better foundation for qualitative discrimination within the sedimentary columnwhether shale, slate, sandstone, or others-the same as for metamorphic or intrusive rocks to moderate depths of 1,000-1,500 ft. He applied the technique to a survey over a prospective dam site, with the result that the depth calculated for the section across the magnetic "low" was $75^{\prime}$, or the average $1 / 2\left(97^{\prime}+75^{\prime}\right)=86^{\prime}$, which corresponds well with the actual findings of $88^{\prime}$.-W. A.

5904. Minakami, Takesi, Magnetic surveys of the Volcano Asama, part 2: Tokyo Imp. Univ., Earthquake Research Inst., Bull., vol. 18, No. 2, pp. 178-251, 1940.

In 1937 the author observed the magnetic inclination at 80 stations near the crater of Asama Volcano, at the foot of the volcano, and midway between the crater and the foot. The results of the surveys were reported previously (see Geophys. Abstracts 98, No. 5028). In the present survey the author determined the declination, the horizontal intensity, and the dip near the volcano, and on the basis of the magnetic anomalies obtained he deduced the structure of the volcano and also investigated the magnetic properties of the rocks composing the volcano. He then calculated the homogeneous magnetization of an oblate ellipsoid having approximately the surface and the volume of 
the volcano, as the result of which he made clear that the anomalies of each element agree with the theoretical result within the accuracy of the assumptions made in the calculation, and also that the mean magnetic susceptibility of the volcano obtained by the same calculation is not unreasonable, considering the physical properties of the lava of Asama. Consequently he concluded that the magnetic anomaly is caused mainly by magnetization of the volcano itself through induction of the earth's magnetic field.-W. $A$.

5905. Nagata, Takesi, On the natural remanent magnetization of the lava composing the central core of Mihara Volcano: Tokyo Imp. Univ., Earthquake Research Inst., Bull., vol. 18, No. 2, pp. 281-288, 1940.

In a previous paper (see Geophys. Abstracts 103, No. 5772) the writer described the magnetic susceptibility and residual magnetization of several samples of rocks ejected from Mihara Volcano. The values of the magnetic susceptibility of the rocks ejected from the central cone were smaller than were expected from the results of a magnetic survey around the crater of the volcano. The small values were probably due to the natural remanent magnetization in the rocks of the central cone. A knowledge of the direction and intensity of the natural remanent magnetization of rocks is therefore of importance not only in problems concerning the interpretation of the results of magnetic surveys, but also in the study of magnetic properties of rocks. In this article the writer describes the magnetometric method he used in determining the direction and intensity of the natural remanent. magnetization of sereral samples of rocks that were ejected from the central cone of Mihara. $\mathrm{He}$ also describes the instrument he used. and tabulates the observed results of the intensity and direction of natural remanent magnetization of the rocks. The results show that the direction of the natural remanent magnetization is nearly equal to the direction of the present geomagnetic force. On the basis of his observations he concludes that the anomalous distribution of geomagnetic declination around the crater of Mihara is due to both induced magnetism and remanent magnetization.-W. $A$.

5906. Shirkie, J. T., Magnetic explorations of prospects: Canadian Min. Jour., vol. 61, No. 11, pp. 729-732, Gardenvale, Quebec, 1940.

The writer compares the instruments ordinarily used in magnetic surveys-the dip needle, magnetometer, and variometer-with regard to their common qualifications and indicates the most economical field for the use of each. He concludes: "Minerals that are not themselves magnetic are often associated with basic dikes or other definitelyi magnetic bodies. When this is the case the structure may be drawn from the results of a magnetic survey and the position of ore bodies inferred from the map. Isoclinal lines along the strikes of a dike are crowded and irregular. Variometers may be used to detect faults even in sedimentary strata, but they must be read at very frequent intervals along the traverse. One or two preliminary traverses should always be made with a dip needle to get an approximate idea of the anomalies present. When this is known the best instrument to use in the survey may be selected." $-W$. A. 
5907. Strona, A. A., Geophysical prospecting for studying deposits in northern regions [in Russian]: Razvedka Nedr, vol. 10, No. 7, pp. 41-42, Moscow, 1940.

Lack of visible traces of Quaternary sedimentation and great thickness of alluvial covers necessitate the application of geophysical exploration in northern regions of the Union of Soviet Socialist Republics. From the results of preliminary magnetic surveys near Lake Shano, 30 kim. from the city of Pudoja, in the Pejma River region, at Lake Moshensk, and elsewhere, intensities of maximum $Z a$ were between 2,000 $\gamma$ and $7,000 \gamma$. The writer recommends detailed magnetic, gravitational, and electrical methods of prospecting in these regions.-W. $A$.

5908. Swanson, C. O., The use of the dip needle in mapping structure: Canadian Min. Met. Bull., No. 345, Trans. section, 1p. 1-11, Montreal, 1941.

The writer presents two ways of using the dip needle in discovering and tracing mineral deposits-the direct and indirect methods. The direct method discovers or follows certain ore bodies br virtue of their magnetic properties; it demands little or no knowledge of geologic conditions. The indirect method uses the dip needle as an aid to purely geologic studies in working out the structure of a mineralized area. Accorcling to the writer's experience the indirect method is used four or five times more often than the direct method.

The purpose of this article is to outline principles and practices of using the dip. needle in working out geologic structure. These he discusses under the headings: (1) General principles; (2) mechanics of the dip needle; (3) adjusting the instrument; (4) field practice; (5) interpretation of magnetic data ; and (6) calculation of sensitivity of the dip needle.-W. $A$.

5909. Webb, E. R., Subsurface dip and strike determined by newly developed polar-core orientation: Mining and Metallurgy, vol. 21, No. 408, pp. 553-555, New York, 1940.

The writer discusses a new laboratory method for determining the dip and strike of subsurface structures, as well as the direction of fault planes traversing them. He describes the instrument used and the procedure. The metbod, called polar-core orientation uses the magnetic properties of borehole cores. The interpretation of the resulting curves traced on sensitized paper locates the position of the northsouth magnetic poles in respect to the reference lines on the core sample. The chief advantages gained by employing this method are that drilling operations may proceed witliout interruption and no special equipment is required at the location. Also it is possible to check previously cored material, provided its top is known.-W. $A$.

\section{SEISMIC METHODS}

5910. Adkins, J. N., The Alaskan earthquake of July 22, 1937: Seismol. Soc. America Bull., vol. 30, No. 4, pp. 353-376, Berkeley, Calif., 1940.

The study of the Alaskan earthquake of July 22, 1937, is based on the examination of original seismograms and photostatic copies from seismological observatories throughout the world. The arrival times of $P$ at 71 stations were used in locating the epicenter. By Geiger's method 
and the use of Jeffreys' traveltimes, the position of the epicenter was found to be: geographical latitude $64.67 \pm 0.04^{\circ}$ N., longitude $146.58 \pm 0.12^{\circ} \mathrm{W}$., and the time of occurrence to be $17^{\mathrm{h}} 9^{\prime \prime} 30.0 \pm 0.25^{s} \mathrm{U}$. T. The epicenter lies in the Yukon-Tanana upland in central Alaska, which is not a region of frequent major earthquakes. The disagreement caused by the apparently early arrivals at College and Sitka was reduced by replacing the standard traveltime curve of $P$ by a linear traveltime curve in the interval of epicentral distance $0^{\circ}$ to $16^{\circ}$ and by interpreting the first arrival at College as $\bar{P}$. It was possible to determine the direction of the first motion of $P$ for 51 stations. The olsserved distribution of first motion and the geologic trends in the region of the epicenter are consistent with the earthquake's having been caused by movement along a fault with strike between N. $30^{\circ}$ E. and N. $37^{\circ}$. E., and dip between $64^{\circ}$ and $71^{\circ}$ to the southeast, in which the southeast side of the fault was displaced relatively northeastward with the line of movement pitching between $12^{\circ}$ and $16^{\circ}$ NIE. A wave designated $F$ (for "false $S$ ") was found to precede $S$ on the records by 20 " to $55^{\prime}$, depending on the epicentral distance. The wave is longitudinal in type, and the arrival times define a linear traveltime curve. It is suggested that this wave may be a longitudinal surface wave of the type proposed by Nakano, produced at the surface of the earth by the arrival of a transverse wave which has been reflected at a surface of discontinuity within the earth. The records show two impulses near the time when $S$ is expected. The average time interval between the two impulses is 11.3". The first, called $S_{\mathrm{t}}$, has a plane of vibration intermediate in direction between the plane of propagation and the normal thereto. The second impulse, called $S_{2}$, is nearly pure $S H_{2}$ movement.Author's abstract.

5911. Baird, H. F., and Banwell, C. J., Recording of air-pressure oscillations associated with microseisms at Christchurch: New Zealand Jour. Sci. Technology, General Section, vol. 21, No. 6b, pp. 314b-329b, Wellington, 1940.

With apparatus first devised in 1936, the authors discovered that microseisms at Christchurch are accompanied by very small oscillations of air pressure. They describe not only an apparatus for detecting minute pressure changes but also the air-pressure oscillations, in which they refer to microseisms, particularly in regard to the theory that they arise from the beating of the sea on extended steep coasts.-Author's abstract, " condensed by W. $A$.

5912. Birch, Francis, and Bancroft, Dennison, New measurements of the rigidity of rocks at high pressure: Jour. Geology, vol. 48, No. 7, pp. 752-766, Chicago, 1940.

New dynamical measurements of the velocity of shear waves and of the rigidity at high pressure are presented for a few igneous rocks and for a group of sedimentary and metamorphic rocks from the Boston area. The results include the changes of velocity on heating to $150^{\circ} \mathrm{C}$. at $4,000 \mathrm{~kg} . / \mathrm{cm} .^{2}$ and at $9,000 \mathrm{~kg} . / \mathrm{cm} .^{2}$ for the igneous rocks, at 4,000 kg. $/ \mathrm{cm}^{2}$ for the other rocks. The dependence of velocity upon composition is briefly discussed.-Authors' abstract. 
5913. Bullard, Đ. C., Gaskkell, T. F., Harland, W. B., and Kerr-Grant, C., Seismic investigations on the Paleozoic floor of eastern England: Royal Soc. Philos. Trans., A, 239, pp. 29-94, July 4, 1940.

The depth of the Paleozoic floor under part of eastern England has been investigated by the refraction-seismic method. Records have been taken every 200 feet along lines 4,000-8,000 feet long; such detailed shooting enables various sources of uncertainty in the results to be investigated. The interpretation of the seismic results required a more thorough knowledge of the contours of the Jurassic and Cretaceous than was available; the data from boreholes and outcrops have therefore been collected and are presented in the form of contoured maps showing the depths of various horizons and the thicknesses of rock between them. A map of the form of the Palezoic floor and a discussion of its constitution are also given. The latter is based on a reexamination of the borehole cores and on the seismic velocities.-Authors' abstract.

5914. Carder, D. S., Response of a torsion seismometer to sustained vibrations: Seismol. Soc. America Bull., vol. 30, No. 4, pp. 343-352, Berkeley, Calif., 1940.

The vibration meter dereloped by the United States Coast and Geodetic Survey and used in nearly all its studies on vibration is essentially a torsion seismometer of the type described by Anderson and Wood. The inertia mass is suspended eccentrically on a nearly vertical fiber so that it acts almost as a horizontal pendulum, the period of which is controlled by the torsional reaction of the fiber and a small gravity component. Optical registration and electromagnetic damping are provided. A sharp flow or high-frequency, vibration will set the whole suspension into so-callèd "bowistring vibration," which" is similar to that of a weighted string. In this article the writer considers especially the behavior of one of these meters when it is subjected to sustained vibrations in the frequency range of this bowstring vibration. The instrument tested is one of the survey's loop-suspension vibration meters. A shaking table of the type described by McComb and Wenner provided sustained vii : brations - W A.

5915. Ewing; Maurice, Woollard, G. P., and Vine, A. C., Geophysical investigations in the emerged and submerged Atlantic Coastal Plain; Part 4, Cape May, N J section: Geol. Soc. America Buli, rol 51, No: 12, pt. 1, pp. 1821-1840, Washington, D, C, 1940.

Seismic-refraction measurements across the New Jersey Coastal Plain, from Bridgeport on Delaware Bay to Avalon on the Atlantic coast, have been made as a continuation of similar measurements of the depth of the crystalline basement made in 1935 at Cape Henry, Va., and Woods Hole, Mass., and in 1937 at Barnegat Bay, N. J. The standard technique

$\therefore \because \quad$ for seismic-refraction measurements was followed. Three seismic disbottom of the surface gravels covering this part of New Jersey. These discontinuities appear to have the same geologic equivalents as were noted on the Barnegat Bay seismic section. The observed depths are in agreement with the available well.data, and the seismic-velocity variations noted for the basement discontinuity indicate similar changes in basement lithology as those found along the Barnegat Bay seismic section.-Authors' abstract. 
5916. Förtsch, O., Ableitung des von der Frequenz unabhängigen Absorptionscoefficienten aus Maschinenschwingungen [Derivation of absorption coefficients independent of frequency from oscillations of machines]: Zeitschr. Geophysik, vol. 16, No. 1/2, pp. 57-84, Brunswick, 1940.

Absorption coefficients calculated according to well-known expansion formulas for sinusoidal oscillations of the ground produced by machines depend always on the frequency. If the distances are measured not in meters but in wave lengths, the coefficients obtained will not depend on the determined values of oscillation: they will only characterize the constitution of the ground. This is proved by theoretical considerations and measurements. An important explanation is also obtained of the process of propagation of oscillations. The author discusses and proves the existence of a connection between the coefficient of absorption of ground oscillations and the ratio of damping of bar oscillations, as well as the connection between the first and the ratio of damping of natural oscillations of the subsoil.-Author's abstract, translated by W. A.

5917. Hafner, W., The seismic-velocity distribution in the Tertiary basins of California: Seismol. Soc. America Bull,, vol. 30, No. 4, pp. 309-326, Berkeley, Calif., 1940.

During seismographic work in recent years the larger oil companies have accumulated a great deal of information on the vertical and lateral variations of seismic velocity in the major Tertiary basins of California. The purpose of the present paper is to give the results of a series of velocity surveys and to discuss their bearing on some of the problems encountered in seismic work. The author describes (1) methods of obtaining information on velocity distribution, (2) the well-velocity method, (3) the analysis of results from California well-velocity data, (4) lateral changes in the velocity distribution as revealed by observed time-depth curves, (5) the position of isovelocity surfaces or speed laycrs, and (6) the comparison with sedimentary basins outside California.-W. A.

5918. Hagiwara, Takahiro, The Ogasima earthquake and its aftershocks: Tokyo Imp. Univ., Earthquake Research Inst., Bull., vol. 18, No. 2, pp. 252-264, 1840.

The writer has determined the epicenter of the Ogasima earthquake from seismological data obtaned at stations within a radius of $200 \mathrm{~km}$. from the epicenter. He describes the aftershocks that he observed and calculates errors in hypocentral position. $-W . A$.

5919. Hagiwara, Takahiro, and Omote, Syunitiro, Seismic prospecting on a sea bottom: Tokyo Imp. Univ., Earthquake Research Inst., Bull., vol. 18, No. 2, pp. 305-317, 1940.

The writers describe seismic prospecting on a sea bottom to examine the geologic structure of a coal field. Prospecting extended about $9 \mathrm{~km}$. offshore, one observation point having been on an islet and another on a shoal in the bay. They used a mechano-optical seismograph on the islet and an electromagnetic seismograph of moving coil type on the shoul. They describe the seismographs and field work and show: the results of their observations in diagrams and tables. $-W$. $A$. 
5920. Kamen-Kaye, M., Seismic-refraction studies in the Orinoco basin of deposition, Venezuela: Geophysics, vol. 5, No. 4, pp. 385-392, Menasha, Wis., 1940.

The progress of seismic-refraction methods in the Orinoco embayment is briefly sketched. Uniformity of post-basement velocities and relations to compaction are noted and unusual velocities analyzed. The author's use of flexure-time contours is described, and the effect of basement velocity variation on flexure time is presented empirically.-Author's abstract.

5921. Leet, L. D., Adapting the Milne-Shaw seismograph to registration of diurnal tilts: Seismol. Soc. America Bull., vol. 30, No. 4, pp. 327-330, Berkeley, Calif., 1940.

Among the instruments first operated in the Oak Ridge vault of the Harvard Seismograph Station were Mine-Shaw seismographs. It was soon discovered that systematic variations in the spacing of the lines on the seismograms correlated with the oceanic tides in Boston Harbor. The Oak Ridge vault is about 30 miles from the nearest point on the coast and 150 miles from the center of the Gulf of Maine. The MilneShaw instruments have now been adapted to operate only for the registration of diurnal tilts. The first step in the adaptation was to replace the original drum-drive clockworks with a Telechron motor, which drives a gear train that gives the drum one complete rotation every 3 days. The recording paper travels slightly more than onefourth inch an hour. The installation is illustrated. A new source of light that was necessary is described. The effectiveness of the system is illustrated by a sample record.-W. $A$.

5922. Lynch, Joseph, What is the state of the earth's core?: Seismol. Soc. America Bull., vol. 30, No. 4, pp. 337-342, Berkeley, Calif., 1940.

Seismology has proved that a definite core exists within the earth, its radius being roughly half that of the earth. The depth of the core has been shown both by the reflection of seismic waves from it and by the refraction of seismic waves through it. There are two schools of thought among students of earth science in regard to the core: one holds that the core is liquid, the other that. it is solid. The writer discusses the reasons advanced by both schools and proposes a. solid to represent the state of the core.-W. $A$.

5923. Lynch, W. A., The energy of local earthquakes recorded at Fordham: Seismol. Soc. America Bull., vol. 30, No. 4, pp. 331-336, Berkeley, Calif., 1940.

Rough calculations of the energy of local earthquakes registered at Fordham on the vertical Benioff seismograph have yielded results varying from $3.4 \times 10^{12}$ e. to $3.7 \times 10^{15}$ e. for 13 different shocks. Numerous assumptions render the values uncertain in absolute magnitude, but it is believed that they are correct in order of magnitude. This belief is strengthened by comparison of the values with (1) energy data on local earthquakes collected in southern California, (2) estimates based on observational evidence, and (3) the computed wave energy of a quarry blast of known total energy. Copies of the records of earthquakes and of the quarry blast are shown.-Author's abstract. 
5924. Matuzawa, Takeo, Hayakawa, Masami, Hattori, Yasumasa, Kaneko, Tetuiti, and Miyamura, Setumi, Erdbebenhäufigkeit in Bezug auf die Stellung der Sonne und des Mondes [Frequency of earthquakes in relation to the position of the sun and the moon]: Tokyo Imp. Univ., Earthquake Research Inst., Bull., vol. 18, No. 2, pp. 265-280, 1940.

Variation in frequency of earthquakes has regional characteristics. Yearly periodicity probably exists in the Japan-Philippine zone-that is, along the eastern coastal line of Asia-with maximum frequency of great earthquakes during summer. Half-year periodicity is observed along the western coastal zone of South America with maximum frequencies during summer and winter. Synodic half-monthly periods also probably exist during the occurrence of great earthquakes. Seasonal variations probably depend mainly on the meteorological influence of the sun and on the influence of monthly variations of the tides.Authors' abstract, translated by W. A.

5925. McCready, H. J., Shot-hole characteristics in reflection seismology: Geophysics, vol. 5, No. 4, pp. 373-381, Menasha, Wis., 1940.

The influence of shot-hole characteristics on seismograms is discussed in some detail. Modifications in the formations surrounding the shot hole caused by successive shots result in compaction or aeration affecting changes in delay times as well as changes in character of the recorded events. The importance of considering these effects in the interpretation of seismograph records and some methods of alleviating these problems by suitable field technique are discussed.-Author's abstract.

5926. Pospelov, P. A., Results of seismic work in the Maineft region [in Russian] : Razvedka Nedr, vol. 10, No. 9, pp. 28-37, Moscow, 1940.

J.he writer gives a description of the seismic-prospecting work of $\mathbf{1 9 3 6}$ and 1937 in the Apsheron-Khadijinsk oil-bearing area and in the Shirvansk region. The seismic-reflection method was used. Sections of reflecting surfaces were determined up to a total length of $52.707 \mathrm{~km}$. The writer gives structural maps of the regions investigated. Summarizing the results of the preliminary surveys, he says he is convinced that notwithstanding unfarorable external conditions (relief, woods) and geologic conditions (lenslike structure and wedging in of sandy formations) the seismic-reflection method can be successfully applied in the areas investigated. Correlation of the results is impossible without well records. Interpretation of the results of the survey should be made very carefully owing to the ruptures of single parts of the reflecting surfaces. The absence of a unit reflecting surface underlying these areas is a great handicap. $-W . A$.

5927. Progress in seismology [editorial]: Nature, vol. 146, No. 3702 , p. 496, London, 1940.

The forty-fifth report of the British Association Committee on seismological investigations was to have been presented at a meeting at Reading. Although this meeting was canceled, the report is now in print. It contains information on the progress of seismology in Great Britain, on the distribution of seismographs, on the equipment of stations in the British Empire, on the publication of the new seismological tables by $407408-41-3$ 
Jeffreys and Bullen, and on investigations concerning a series of British earthquakes that occurred in 1939.-W. $A$.

5928. Regula, Walter, Untersuchungen elastischer Eigenschaften von Gesteinsstïben [Investigations of elastic properties of rock bars]: Zeitschr. Geophysik, vol. 16, No. 1/2, pp. 40-56, Brunswick, 1940.

After a short account of methods hitherto applied to the investigation of elastic properties of rock bars and of the results obtained, the author discusses methods for determining the modulus of elasticity and the modulus of torsion of rock bars in a statical and dynamical way. After observing great discrepancies in the moduli obtained by different methods, he believes that the main discrepancy was due to tension. He examined-on bars having a square cross section-the influence of tensior and the curvature of a cross section and derived a new formula for calculating specific frequency during torsion oscillations for bars having a great swinging mass. He determined Poisson's ratio from the moduli of elasticity and compared the torsion with that obtained from seismic measurements. He discusses finally the elastic hysteresis of rocks.Author's abstract, translated by W. A.

5929. Ricker, Norman, The form and nature of seismic waves and the structure of seismograms: Geophysics, vol. 5, No. 4, pp. 348-366, Menasha, Wis., 1940.

A theory is presented to account for the structure of seismograms. It is demonstrated mathematically that a sharp seismic disturbance gives rise to a traveling "wavelet" of a shape determined by the nature of the earth's absorption spectrum for elastic waves, and that a seismogram is composed of a succession of these wavelets, generally overlapping but sometimes in the clear. It is further brought out that it is the center of the wavelet which travels with a velocity characteristic of the medium, and that the wavelet broadens as it moves along in accordance with a definite law. Experimental support of the theory also is presented.Author's abstract.

5930. Sezawa, Katsutada, and Kanai, Kiyoshi, The action of soil layers and of the ocean as dynamic dampers to seismic surface waves, and notes on a few previous papers: Tokyo Imp. Univ., Earthquake Research Inst., Bull., vol. 18, No. 2, pp. 150-168, 1940.

By mathematical investigation the writers ascertained that a surface soil layer serves as a dynamic damper to seismic surface waves, provided that the layer is fairly thick, slightly elastic, and viscous. The

attenuation coefficient of the boundary waves in a soil layer with a given viscosity that rests on a semi-infinite, subjacent, elastic medium without viscosity is much greater than the coefficient of Rayleigh waves transmitted through a semi-infinite body with the same elasticity as that of the subjacent medium and with the same viscosity as that of the soil lajer. Although the coefficient of the waves in the surface layer and the subjacent medium (when both are viscous) is naturally greater than when the surface layer alone is viscous, the increment of the coefficient would not be very marked. Sea water can hardly be said to contribute to the damping of seismic boundary waves, for the viscosity of water is very small compared with that of solid matter. 
In the present paper the writers have assumed, for convenlence, the existence of vibrators of relatively simple type and have not considered the actual medium in the soil layer. The treatment where the soil layer is really visco-elastic and is a continuous medium will be discussed in the near future.-Authors' abstract.

The notes added to this paper concern some corrections to be made in the writers' following papers, which have been discussed previously: (1) Damping of periodic visco-elastic waves with increase in focal distance, parts 1 and 2 (see Geophys. Abstracts 96 and 99, Nos. 4818 and 5209) ; (2) A kind of wave transmitted over a semi-infinite solid body of varying elasticity (see Geophys. Abstracts 32, No. 521); and (3) On shallow-water waves transmitted in the direction parallel to a sea coast, with special reference to Love waves in heterogeneous media (see Earthquake Research Inst. Bull., vol. 17, No. 4, 1939).-W. A.

5931. Sezawa, Katsutada, and Kanai, Kiyoshi, Viscosity distribution within the earth (preliminary notes): Tokyo Imp. Univ., Earthquake Research Inst., Bull., vol. 18, No. 2, pp. 169-177, 1940.

From the analysis of seismic records and from the theory of surface waves as well as of bodily waves, we ascertained that the coefficient of viscosity of the rocky shell of the earth lies between $10^{10}$ and $10^{\circ}$ in C. G. S. units. The coefficient near the surface rather exceeds that at depth. Inasmuch as damping action is reduced with increase in elasticity, moreover, the effective viscosity at depth is much less than the viscosity as actually estimated from the analysis. From Jeffreys' investigation on the persistence in variation in latitude and the damping of seismic waves, the viscosity of the earth's crust is about $5 \times 10^{20}$ in C. G. S. units. The difference is probably due to the fact that we assumed only one kind of viscosity, whereas Jeffreys assumed two, namely, elastico-viscosity and firmo-viscosity.-Authors' abstract.

5932. Toperczer, Max, Beitrag zur theoretischen Behandlung des Erdbebenstosses [Contribution to the theoretical investigation of earthquake shock] : Akad. Wiss. Wien, Sitzungsber., Abt. 2a, vol. 148, No. 1/2, pp. 1-32, Vienna, 1939.

This mathematical discussion attempts to derive a function from such properties inrolved in earthquake shock as may explain such shock in detail. The function that the author investigated in this article consists merely in a mathematical description of facts obtained in an empirical way. $-W . A$.

5933. Washburn, Harold, and Olesen, Raymond, Transient testing of seismicrecording apparatus: Geophysics, vol. 5, No. 4, pp. 337-347, Menasha, Wis., 1940.

A transient generator and shaking table suitable for testing characteristics of seismometers and associated amplifier and recording equipment is described. From variable-area sound-on-film records representing idealized transients or actual field seismograph recordings, the generator and shaking table provide a high-fidelity conversion to mechanical motion of the test table. The special experimental truck used in obtaining test records is also described briefly.-Authors' abstract. 
5934. Wolf, Alfred, The time delay of a wave group in the weathered layer: Geophysics, vol. 5, No. 4, pp. 367-372, Menasha, Wis., 1940.

Ground motion observed in seismic prospecting can be regarded as being composed of groups of waves of some predominant frequency. The velocity of propagation of such wave groups in the earth is the group velocity. A detailed application is made to the calculation of the time delay of a reflection wave group passing through the weathered layer. It appears that the weathering time of a reflection is a function of its frequency and that it may differ from the weathering time of first-arrival waves.-Author's abstract.

5935. Zirbel, N. N., Michigan weathering: Geophysics, vol. 5, No. 4, pp. 382-384, Menasha, Wis., 1940.

In this paper the weathering conditions found in the Michigan Basin are discussed. It is shown that the depth of the drift cannot generally be determined from weathering profiles, and a method for correcting reflection depths under these conditions is suggested.-Author's abstract.

\section{ELECTRICAL METHODS}

5936. Börner, Rudolf, Abgrenzung diluvialer Auswaschungszonen in der mitteldeutschen Braunkohle durch.das "Geoskop"-Verfahren [Delimitation of washed-out diluvial zones in the lignite of central Germany by the geoscope method] : Braunkohle, vol. 38, No. 43, pp. 715-717, Halle, 1939.

The following results were obtained from measurements in the Niederlausitz lignite deposits by the geoscope method: (1) Sharp borders between the seams of lignite and the washed-out zones were determined by means of geoscope curves; (2) gradual transition zones were established; (3) zones washed out partly and irregularly were determined by means of latticelike measuring nets; (4) numerical data on the degree of washing out could not be obtained, although it could be determined whether a zone was still worth working, especially where a thin seam was partly washed out and its profitable exploitation became questionable; (5) the results of measurements with the geoscope contradict fully the belief held by professional geophysicists that electrical waves can be applied only to determine the difference in layers that are within a few meters of the surface of the ground. Measurements with the geoscope disclosed seams of lignite at an average depth of 60 m.-Author's abstract, translated by W. A.

5937. Börner, Rudolf, Überblick über den Stand geologisch-bergbaulicher Forschung mit Hilfe des geophysikalischen Messgerätes "Geoskop" [Review of the condition of geologic and mining investigations with the geophysical measuring-apparatus "geoscope"]: Gliickauf, vol. 76, No. 19, pp. 261-268, Essen, 1940.

The writer discusses the construction, method of operation, and application of the geoscope for geologic and mining prospecting without considering physical and theoretical questions. He divides the investlgations into two main groups-tectonic investigations and speciflc delimitations of material and deposits.

The following results may be obtained from investigations of the first group: Determining the disturbances (1) within uncovered coal 
formations; (2) within coal formations having a thick Tertiary covering (to about $500 \mathrm{~m}$.) ; (3) in coal veins covered by Bunter sandstone (to about $400 \mathrm{~m}$.) ; (4) within coal veins having a heavy cover of Cretaceous rocks (to about $800 \mathrm{~m}$.); (5) within the Rhine lignite deposits in spite of considerable covering; and (6) that affect technical construction (strikes, dips, old galleries) to a depth of $5 \mathrm{~m}$. The writer determined exactly all the disturbances mentioned above with regard to their position, direction, strike, dip, and even the approximate degree of the angle of dip. He recommends application of the geoscope for obtaining information on suitable places for grounding lightning rods.

A summary of the results obtained in the group of specific measurements follows: (1) Information on ganguelike metallic and nonmetallic deposits, and determination of the approximate thickness and of the direction of the strike and dip; (2) determination of lenticular and nestlike deposits; (3) determination of deposits having the form of strata or stocks; (4) delimitation of washed-out diluvial channels and other lignite deposits; (5) delimitation of the extensions of salt domes; and (6) complete agreement of oil investigations with the data obtained by boring, even in deep-lying deposits.

All the cases mentioned have been proved by practice.

The results may change according to the geologic conditions of the regions investigated.-Author's abstract, translated by W. A.

5938. Culbertson, J. A., Downdip Wilcox (Eocene) of coastal Texas and Louisiana: Am. Assoc. Petroleum Geologists Bull., vol. 24, No. 11, pp. 18911922, Tulsa, Okla., 1940.

The Wilcox series was indicated approximately 2 years ago as a major deep objective, and the drilling campaign continues unabated. The writer endeavors to analyze these new data in the light of regional stratigraphy and further evaluation of oil potentialities. A contour map, based on subsea depths to the top of the Wilcox, is offered as evidence on the regional structure of the series. Eight electrical-log dip sections, including the Claiborne series in addition to the Wilcox, illustrate the electrical character and thickness of the sediments and the relation of Wilcox deposition to that of the younger series. Variations in amount and date of coastal geosynclinal subsidence are discussed. Possible relations of the basal Claiborne or Carrizo formation to the downdip Wilcox sands are considered. Attention is called to the local occurrence of a "Discocyclina" zone, which may have a future value in regional correlations. Coregraphs and a table of porosities and permeabilities of Wilcox sands in several deep wells offer evidence of a downdip economic limit to Wilcox production. Other factors of importance in Wilcox prospecting are discussed.-Author's abstract.

5939. Fritsch, Volker, Der funkgeologische Nachweis von Gas und Wassereinschlïssen [Radiogeologic information concerning gas and water inclusions] : Glückauf, vol. 76, No. 36, pp. 488-493, Essen, 1940.

Information concerning gas and water inclusions in rocks and salt deposits may be obtained by using high-frequency methods of measurement (radioprospecting). The methods will measure changes in conducting currents as well as in displacement currents. The distinction 
of nonconductors becomes possible only so long as they produce anomalous dielectric constants. Instruments available at present are already of such a high sensitivity that they can be applied in practice. The instruments may be manufactured also in arrangements applicable to special conditions.-Author's abstract, translated by W. A.

5940. Fritsch, Volker, Die funkgeologische Untersuchung des Zinnobervorkommens ron Schönbach bei Eger (Sudetenland) [Radiogeologic investigation of cinnabar deposits of Schönbach, near Eger (Sudetenland)]: Neues Jahrbuch für Mineralogie, Geologie und Palïontologie, Abt. B, vol. 84, No. 1, pp. 90-116, Stuttgart, 1940.

The writer considers radiogeologic investigations of cinnabar deposits, described in this article, to be of interest to geologists as they show the many relations that exist between geology, hydrology, and geoelectrics. He attempts to show how far geologic and hydrologic assumptions are to be considered during radioprospecting and in what way these factors may predetermine the kind of method of radioprospecting to be applied.

Afier a general geologic description of the deposits and of the geophysical problems involved, he gives the following details: (1) Methods of radioprospecting applied, principles of the methods, and distribution of measuring instruments; (2) evaluation of the results of the measurements, illustrated by diagrams; and (3) determination of the geologic structure of the region investigated, based on the results of radioprospecting. . He concludes that a rather clear picture of the structure has been obtained and that mining operations based on measurements of the deposits can be started.-W. $A$.

5941. Gurevich, B. L., and Zagarmistr, A. M., Deep electrical soundings in connection with the search for oil-bearing structures in the central parts of the U. S. S. R. [in Russian] : Razvedka Nedr, vol. 10, No. 7, pp. 26-31, Moscow, 1940.

The first deep electrical soundings in the Union of Soviet Socialist Republics were made in 1938 in the region of the Don-Medveditsk anticline. The problem consisted in determining the details of the structure of the fold and, in particular, the existence of terrigeneous deposits in the Carboniferous system. It was solved satisfactorily by means of verticalelectrical soundings, with distance between the electrodes equal to 8,000 m. A complicated geologic-electrical profile shows seven electrical horizons down to about $500 \mathrm{~m}$. To obtain information on deposits having properties of electrical conductivity at still greater depths, the authors made trials of vertical-electrical soundings, with distance $A B$ between the electrodes up to $20 \mathrm{~km}$. The results of the surveys, with $A B=12.14$ $\mathrm{km}$. and maximum $A B=20 \mathrm{~km}$., are shown on three profiles. A crystalline massif with resistance of 12 to $15 \mathrm{ohm}-\mathrm{m}$. has been determined at a depth of 2,500-3,000 m.

For soundings at great depths the authors recommend the method of continuous measurements (conveyer method) by measuring simultaneously the following: Shallow vertical-electrical sounding with $A B=1,000$ m., medium vertical-electrical sounding with $A B=6,000-8,000 \mathrm{~m}$., and deep vertical-electrical sounding with $A B=20,000 \mathrm{~m}$. For these measurements 10 batteries of $30 \mathrm{kc}$, connected in series, were used to supply current. When $A B=16$ to $20 \mathrm{~km}$., the current is fed into the ground through 20-25 long steel rods $(1.75 \mathrm{~m}$.). Maximum intensity of the 
current obtained did not exceed $1.5 \mathrm{a}$. Values of the measured differences in potential varied between 0.12 and $0.23 \mathrm{~m}$.-v.

For more reliable results the authors recommend that the sensitivity of the measuring apparatus be increased and that the accuracy in measuring small values of potential difference be improved.-W. $A$.

5942. Hayward, J. T., Development of continuous logging at rotary drilling wells: California Oil World, vol. 33, Nos. 23 and 24, pp. 12-18, 21-22, Los Angeles, 1940.

The author discusses the development of procedure and equipment now being used successfully in detecting relatively small quantities of oil, water, and gas brought to the surface from the bottom of a.dilling well by mud-circulating fluid used in rotary drilling, together with the method used in determining the depths of the horizons where the samples entered the well bore. He describes in detail a number of instruments that have been placed upon a panel and installed in a trailer; the trailer is moved from location to location as the drilling rig is moved. Most of these instruments are concerned with the logging of the well as drilling progresses. With these new instruments and methods it now is possible to drill ahead continuously, and to know fairly accurately the type of formation that is being drilled through-its oil, water, and gas contents, and its depth. Information of this nature, obtainable while drilling, not only is quite helpful in determining completion procedure but also may become useful in the later life of the well in producing or reconditioning operations.-Author's abstract.

5943. Martienssen, Oscar, Gebirgsschichtenbestimmung in Tiefbohrlöchern [Determining rock strata in deep boreholes] : Zeitschr. prakt. Geologie, vol. 48, No. 7, pp. 73-78, Halle, 1940.

The writer describes the following three methods of determining rock strata in deep boreholes: (1) Resistance method; (2) method of measuring the current; and (3) method of measuring high frequency. Curves obtained from the application of these three methods serve as examples for explaining them. After investigating several boreholes the writer shows that the curves obtained by these three methods are similar.W. A.

5944. Mercanton, P. L., Regarding resistivity in electrical prospecting-A practice to be rejected: Internat. Assoc. Terres. Magn. and Electr., Washington Assembly, Document T 107, September 1939.

Attention is called to the incorrect use of the expression for measuring resistivity values in ohms per cubic units. Motion presented that above assembly note that only the correct unit of ohms times centimeter be employed (or ohms times a distance unit).-D. W., Mines Mag., vol. 30, No. 11,1940 .

5945. Ogilvi, A. A., Electrical prospecting in underground workings [in Russian] : Razvedka Nedr, vol. 10, No. 7, pp. 31-35, Moscow, 1940.

The writer briefly describes experimental electrical prospecting in mines of the Balcan tungsten deposits in the southern Urals, where profiling, sounding, and natural-potential methods were applied, and he gives general information on applying the resistivity method in mines. Electrical prospecting was made at five horizons: $60 \mathrm{~m} ., 80 \mathrm{~m} ., 90 \mathrm{~m}$., 
$110 \mathrm{~m}$., and $120 \mathrm{~m}$. The problem consisted in microprofiling. The results proved that even the smallest changes in properties of rocks, which sometimes could not be established by geologic data, were clearly visible on the resistivity profiles. Resistivity profiles obtained at the 120-m. horizon illustrate the work ; results obtained from the sounding measurements were uninteresting. The natural-potential method revealed the existence of zones of spontaneous polarization of considerable value (up to $50 \mathrm{~m}$.), which were probably caused by the infiltration of water and by physico-chemical processes.-W. $A$.

5946. Schulte, Fr., Beitrag zur geologisch-bergbaulichen Forschung mit Hilfe des geophysikalischen Messgerätes "Geoskop" [Contribution to geologic mining investigation with the aid of the geophysical measuring-instrument "geoscope"] : Glückauf, vol. 76, No. 42, pp. 565-571, Essen, 1940.

On the basis of information obtained from mining, the writer examines the effect on the geoscope of disturbances produced by Carboniferous deposits. He shows that the reaction of the instrument is expressed by rising and descending curves with distinct peaks (maxima). These peaks are the characteristic points of the geoscope curves, and their perpendicular projections downward represent the highest points of the deposits of coal or Bunter sandstone; more precisely, they represent the location of the base of the soft rocks overlying the coal where the deposit is cropping out. By using the geoscope curve, he was thus able to determine the depth of the rocks covering the deposit. The geoscope method offers great advantages to mining.-Author's abstract, translated by W. A.

5947. Shaskolski, V. V., Automatic potentiometer for logging, type PS-2 [in Russian] : Razvedka Nedr, vol. 10, No. 7, pp. 36-38, Moscow, 1940.

The circuit of the new automatic potentiometer for logging wells, developed in the People's Commissariat of Electrical Industry, is shown in a figure. Photographs show the general construction of the apparatus. The time lag of the instrument is less than 2 sec. The apparatus may be operated on a single-phase alternating current of $120,220,380$, or $440 \mathrm{v}$. The results obtained with the new potentiometer will be given after it has been tested in the oil fields.-W. $A$.

5948. Wölk, Ernst, Über das neue geophysikalische Untersuchungsgerät "Geoskop" und seine Verwendungsmöglichkeit im Braunkohlenbergbau [On the new geophysical-prospecting apparatus "geoscope" and its possible application in the lignite mining industry]: Braunkohle, vol. 38, No. 11, pp. 201-208, and No. 12, pp. 221-227, Halle, 1939.

1. Good results were obtained by using the geoscope, notwithstanding the unfavorable conditions in the-Tertiary lignite formations of the lower Rhine expressed by the variation in the throws of the faults and of the overburden.

2. The geoscope is a very compact electrical apparatus, and can be carried easily by two men.

3. Continuous measurements and deflection curves can be made while in the field by carrying the apparatus over the terrain.

4. The faults and zones of disturbance can be determined directly and thus necessitate no troublesome calculations and construction of curves from measured differences in heights. 
5. Cross disturbances are indicated by characteristic maximum points. The line of disturbance may be determined by the direction of the gradual declination of the curve from the maximum value.

6. Several measurements at certain intervals over the disturbance are necessary to determine the strike of a cross fault. The line of the strike of the fault is obtained by connecting single points of intersection of the curves with the line of disturbance.

7. Investigations made over. lignite seams at different depths have proved that the results are not influenced by depth.

8. Deposits may be distinguished by examining the deflections of the geoscope (positive or negative), and from the geoscope values drawn on a map the form of the deposit (whether elongate, round, or irregular) may be coordinated and determined; for example, the following could be determined:

(1) Positive geoscope values: (a) Elongate deposits-faults, zones of disturbance, strikes, dips, and buried metallic objects such as cables and pipes; $(b)$ round and irregular deposits-ores (good electrical conductors) such as iron-ore deposits and buried metallic objects.

(2) Negative geoscope values: (a) Elongate deposits-ores (nonconductors) containing barite, fluorite, and petroliferous substances; (b) roundish and irregular deposits-nonconducting ores, salt domes, oil domes, and collapsed mines, or "broken ground."-Author's abstract, translated by W. A.

\section{RADIOACTIVE METHODS}

5949. Aliverti, Giuseppina, and Lovera, G., Su la misura della radioattivita delle acque; proposta di un nuovo procedimento [On the measurement of the radioactivity of water; suggestion of a new method] : Ricerca sci., vol. 11, No. 2, pp. 235-243, Rome, April 1940.

A method is described for distinguishing between and measuring the quantities of the various radioactive elements present in water. The method consists essentially of two parts: (1) Collection of a radioactive deposit on an electrode, and (2) examination of the electrode deposit in an ionization chamber. Full details are given, and the errors and the sensitivity of the apparatus are discussed.-E. E. W., Sci. Abstracts, vol. 43; No. 512, 1940 .

5950. Howell, L. G., Radioactivity as a geophysical tool: Conference on applied nuclear physics sponsored by the American Institute of Physics in cooperation with the Massachusetts Institute of Technology, October 28-November 2, 1940, pp. 24-25, Cambridge, Mass., 1940.

The writer discusses the application of measurements of radioactivity in geophysical studies both on the surface and in the subsurface of the earth to distinguish underground formations. The gamma-ray logs disclose a striking correlation with electrical logs made in the same wells. The obvious advantage of the gamma-ray method over the electrical method is that logs can be obtained from wells cased with iron pipe. Another application of measuring radioactivity in wells is in the location of cement that has been pumped behind the casing in a well. Carnotite, a radioactive ore, was added to the cement before it was pumped out through perforations or through the lower end of the pipe. The carnotite may be detected by measuring the variations of gamma-ray intensity with depth inside the cașing.-W. $\boldsymbol{A}$. 
5951. Russell, W. L., Well logging by radioactivity: Oil Weekly, vol. 99, No. 10, pp. 16-22, Houston, Tex., 1940.

Aithough electric logs give accurate results, they are entirely limited to open holes. The development of radioactivity logs makes it possible to obtain accurate well $\operatorname{logs}$ through the casing.

After describing briefly radioactivity and the distribution of radioactive matter in rocks, the author describes the instrument used in radioactivity well surveying. He explains in detail (1) the effect of materials in the hole; (2) the preparation of a well for gamma-ray logging; (3) the interpretation of gamma-ray logs; (4) the method of estimating porosity from radioactivity logs; (5) statistical variations; and (6) the accuracy of measurements. In the last part of the article he investigates critically the uses of gamma-ray logs for such purposes as gun-perforating and determining the sample log. Diagrams show radioactivity $\log \mathrm{s}$, and compare a radioactivity $\log$ and an electrical log.-W. A.

\section{GEOTHERMAL METHODS}

5952. Millikan, C. V., Temperature surveys in oil wells : Am. Inst. Min. Met. Eng. Tech. Pub. 1258, 8 pp., New York, 1940, and Oil and Gas Jour., vol. 39, No. 25, pp. 62-63, Tulsa, Okla., 1940.

The writer discusses temperature graphs in relation to their use in solving such specific problems as the casing of leaks and the setting of cement. He describes briefly the types of thermometers that are most adaptable for temperature surveys in oil wells and summarizes the value of a temperature survey as follows: "A temperature survey to show presence and depth of a leak in the casing is not likely to result in any problem of preparing the well or of interpreting the temperatures. The same is true of determinations of top of cement behind pipe. A temperature survey from which it is expected to correlate formations, interpret location of probable oil or gas sands behind casing, or determine gas-oil contact or source of water frequently tax ingenuity to condition the well -so as to obtain temperature anomalies that represent conditions within the well. Temperatures frequently require comparison with electric logs, sample logs, production history, and other information before a reliable interpretation can be made."- $W: A$.

5953. Sezawa, Katsutada, and Kanai, Kiyoshi, Temperature distribution within the earth in its semigaseous state, parts 1, 2, and 3: Tokyo Imp. Univ., Earthquake Res. Inst., Bull., vol. 17, No. 3, pp. 525-537, 1939; vol. 17, No. 4, pp. 675-684, 1939; and vol. 18, No. 1, pp. 27-40, 1940.

A mathematical discussion, from which it is concluded that if the central temperature $T$ of the primitive earth was $(1)<4,000^{\circ} \mathrm{K}$. or (3) $>80,000^{\circ} \mathrm{K}$. the central part would be liquid; but if (2) $5,000^{\circ}<T<50,000^{\circ}$ it would remain gaseous. It is probable that (1) was the original state of the earth, showers of $\mathrm{Fe}$ and $\mathrm{Ni}$ being first formed on cooling.-C. A. S., Sci. Abstracts, vol. 43, No. 512, 1940.

5954. Sezawa, Katsutada, and Kanai, Kiyoshi, The effect of distribution of heat-generating sources on the temperature gradient in the earth's crust: Tokyo Imp. Univ., Earthquake Research Inst., Bull., vol. 18, No. 2, pp. 137-149, 1940.

From the results of mathematical analyses of two problems-(1) the problem of sinusoidal areal distribution of sources in the surface layer 
and (2) that of rectangular areal distribution of sources in the surface layer-the authors conclude as follows: "Although the temperature gradient on the surface of the earth's crust is nearly constant for any place, the intensity of the heat generated in the crust there could differ greatly from that in any other place. Since, from Jeffreys' investigation, the thickness of the heat-generating layer is practically $30 \mathrm{~km}$., the effect of local heat sources of the range from 10 to $20 \mathrm{~km}$. on the gradient is less than 10 percent of that of the uniform sources extending to infinity. It should be remembered, however, that if there were a point source of great intensity, like a volcano, it would be possible for the gradient exactly at that point to be enormous."

In the present investigation, which is concerned only with the temperature gradient on the surface due to any local heat source, the authors have ascertained that the effect of local heat sources on the temperature gradient is rather small.-W. $A$.

5955. Slichter, L. B., The internal heat of the earth: Conference on applied nuclear physics, sponsored by the American Institute of Physics in cooperation with the Massachusetts Institute of Technology, October 28November 2, 1940, pp. 25-26, Cambridge, Mass., 1940.

The writer considers that the six most outstanding factors in the problem of the earth's internal heat are as follows: (1) The gain of heat from radioactive sources in the interior; (2) the loss of heat as measured by the upward heat flux in the earth's crust; (3) the original heat of the earth as represented by the initial temperature distribution when the crust first solidified; (4) the value of the thermal conductivity and its change with depth; (5) the presence or absence of significant heat transport by convection currents in the interior; and (6) the large heat capacity and thermal inertia of the earth. He discusses these six factors and summarizes the discussion by saying: "It is obvious that thermal evidence alone does not suffice to yield. definite results about thermal conditions in the interior. However, evidence from independent sources is sometimes available and helpful. For example, the large increase in electrical conductivity at depths below 500 $\mathrm{km}$. deduced from studies in terrestrial magnetism has significance. More accurate knowledge of the variation of seismic-wave velocities in the mantle may prove helpful. The fluidity of the earth's core, as deduced from several types of geophysical evidence, obviously has important thermal implications. Finally, future contributions from the atomic theory concerning the probable mechanical and thermal constants of rock materials in the deep interior would distinctly advance our deficient understanding of the problem of the earth's internal heat."W. A.

\section{GEOCHEMICAL METHODS}

Note.-No abstracts on geochemical methods in this quarterly number.

\section{UNCLASSIFIED METHODS AND TOPICS RELATED TO GEOPHYSICS}

5956. Blau, L. W., Geophysical exploration: Mining and Metallurgy, vol. 22, No. 410, pp. 78-81, New York, 1941.

In this article the writer reviews briefly the activity of geophysical exploration throughout the world during 1940. He considers that the chief contribution to exploration geophysics in 1940 was the publication 
of the three text books, Geophysical prospecting for oil, by L. L. Nettleton ; Exploration geophysics, by J. J. Jakosky ; and Geophysical exploration, by C. A. Heiland. Activity in geophysical prospecting has decreased except perhaps in Canada because of the new World War. The year was notable for a further decline in new oil-field discoveries, a decline that is attributed partly to the decreased export of oil from the United States and South America, partly to the failure of industry to adopt the new exploration techniques, and partly to its tenacious concentration on structural rather than stratigraphic prospecting. He gives a brief account concerning the outstanding points of the geophysical methods of prospecting (magnetic, gravitational, seismic, electrical, geochemical, geothermal, and radioactive). He concludes by outlining the progress in the logging of wells. $-W . A$.

5957. Elkins, T. A., The reliability of geophysical anomalies on the basis of probability considerations: Geophysics, vol. 5, No. 4, pp. 321-336, Menasha, Wis., 1940.

When data are used which contain random errors, there is always some question as to whether a supposed anomaly may not be real but due only to errors in the data. This paper describes a method of testing this point, which is worked out in detail assuming the Gaussian error law for the case of independent values. Possible applications of the method to the problems of contouring data and of evaluating and ranking anomalies are suggested. Examples of the use of the method on gravity and oil-gas analysis data are also given.-Author's abstract.

5958. Frost, V. L., Ramsey oil pool, Payne County, Okla.: Am. Assoc. Petroleum Geologists Bull., vol. 24, No. 11, pp. 1995-2005, Tulsa, Okla., 1940.

The Ramsey oil pool, located 6 miles southwest of Stillwater, Payne County, Okla., was discovered in 1938. Interesting surface faulting and core-drill data instigated geophysical prospecting in this area and led to the discovery of the pool. The subsurface structure is a flattopped, steeply dipping, almost circular, faulted dome with $130 \mathrm{ft}$. of pre-Pennsylvanian truncation. The producing formation, the First "Wilcox" sand, is a member of the Simpson group of Ordovician age and has a vertical producing range of $189 \mathrm{ft}$. The pool has a proved area of 390 acres and has produced 2,703,013 bbl. of oil to June 1, 1940, which gives an average of $6,931 \mathrm{bbl}$. per proved acre. The present daily allowable is 3,800 from 38 producing wells. The Mid-Continent Petroleum Corporation operates 36 wells, the only other operator being the Stanolind Oil \& Gas Co. with 2 wells.-Author's abstract.

5959. Hubbert, King, The theory of ground-water motion: Jour. Geology, vol. 48, No. 8, pt. 1, pp. 785-944, Chicago, 1940.

The existing analytical treatments of ground-water flow have mostly been founded upon the erroneous conception, borrowed from the theory of the flow of the ideal frictionless fluids of classical hydrodynamics, that ground-water motion is derivable from a velocity potential. This conception is in conformity with the principle of the conservation of matter but not with that of the conservation of energy. In the present paper it is shown that a more exceptionless analytical theory results if a potential, whose value at a given point is defined to be equal to the work required to transform a unit mass of fluid from an arbitrary 
standard state to the state at the point in question, is employed. Denoting this function by $\Phi$, it is shown that the differential equation of fluid flow in an isotropic medium is given by $q=\sigma$ grad $\Phi$, where $q$ is the flow vector whose magnitude is equal to the volume of fluid crossing a unit of area normal to the flow direction in unit time, and $\sigma$ a specific conductivity parameter depending upon both the properties of the fluid and the medium. This is an expression of Darcy's law and is physically as well as mathematically analogous to Ohm's law in electricity and leads to the same deductions in analogous situations. It is shown that $\sigma=\mathrm{K} \rho / \eta$, where $\mathrm{K}$ is the permeability parameter depending upon the geometrical properties of the medium only and $\rho$ and $\eta$ are the density and viscosity, respectively, of the fluid.

The remainder of the paper is devoted to deducing the consequences of Darcy's law as just expressed, with particular regard for the practical problems of ground-water hydrology.-Author's abstract.

5960. Kornfeld, J. A., Geology and economic significance of Mississippi oil development: World Petroleum, vol, 11, No. 3, p. 38, New York, 1940.

The Tinsley field is in the west-central part of the State. It has 11 wells proving an area of 1,200 acres, and its daily production is $2,100 \mathrm{bbl}$. Its discovery led to great exploratory activity in Mississippi. Semicommercial production was found at Jackson in 19:30 in the Selma chalk. In 1932 dead oil was discovered in the Eutaw, near Quitman. Tinsley, opened in 1939, yields oil from the Woodruff sand of the Selma chalk at over 4,500 $\mathrm{ft}$. There is a southerly plunging anticline, apparently a truncated structure of igneous origin, with no free gas, and a sand of variable thickness. The structure was first indicated geologically and then .checked. geophysically. . In January there were 64 geophysical parties at work in Mississippi : 30 seismic, 30 gravity, and 4 magnetic. Various wells have reached igneous rocks in western Mississippi. Some of these are post-early Cretaceous. At Jackson there are igneous rocks. The Jackson gas field covers 7,500 acres. It was discovered in 1930 at a depth of $2,430 \mathrm{ft}$. in the Gulf Cretaceous. Some $84,816,231,000 \mathrm{cu}$. ft. of gas have been recovered. Some of the wells had an oil spray. Unsuccessful attempts have been made to obtain oil and gas production on the broad, gentle Hatchetigbee anticline. In northeastern Mississippi, on the southwest end of the Cincinnati arch, the Mississippian gives gas at Amory (Hartselle and Bethel sands). Tests should be made in the Ordovician

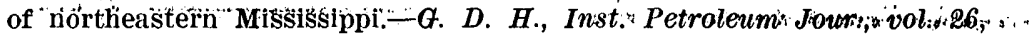
No. 203, 1940.

5691. Kornfeld, J. A., Nebraska joins the oil States: World Petroleum, vol. 11, No. 1, p. 3, New York, 1940.

Commercial oil production was first obtained in Nebraska in November 1939, when a wildcat in the southeast found oil in Silurian limestone. The discovery can be attributed to the reflection seismograph. This well topped the Mississippian limestone at 2,029 $\mathrm{ft}$. and Silurian limestone at $2,288 \mathrm{ft}$. In the first day's pumping, $130 \mathrm{bbl}$. of oil were produced. Glacial deposits are at the surface in this area, resting on Permian and Pennsylvanian. Immediately under the Mississippian are Siluriąn dolomites. - The greatest thickness a Silurian recorded is 450 . ft. Ordovician and Cambro-Ordovician are known to be present, and 
wells have penetrated pre-Cambrian schist. The nearest Siluirian outcrop is 235 miles due east, while the nearest Silurian production is - $\mathbf{1 7 0}$ miles to the southwest in Kansas, where accumulation is the result of pinching out of the Hunton in the flank of the Graber structure. The old Colmar field of Illinois is 250 miles to the east. The local structure of the Falls City field is a secondary fold to the east of the Table Rock anticline, itself the northern extension of the Nemaha Granite Ridge. The structure may be faulted.-G. D. H., Inst. Petroleum Jour., vol. 26, No. 203, 1940.

5962. von "/werger, Rudolf, Die erdölgeologischen Untersuchungen in Westungarn (Transdannbien) und die Erschliessung des ölfeldes von Lispe [Geologic investigations for oil in western Hungary (Transdanubia) and the discovery of the Lispe oil field?: Oel 1. Kohle, vol. 36, No. 40, pp. 427-437, Berlin, 1940.

This article gives a historical outline of the activity of the Hungarian. American oil industry since 1933 in connection with the search for oil in western Hungary. It mentions the following geophysical investigations: (1) Gravity measurements. From 1933 to $1938,9,677$ torsionbalance measurements were made and many gravity anomalies found. The gravimeter was used for close investigation of the anomalies and for drawing a map of isogams. (2) Magnetic measurements. The Askania field balance was used. 'The results served for a better interpretation of the data obtained by gravitational and seismic surveys in determining the structure of the subsoil. (3) Seismic measurements. The seismic-reflection methorls were used. Profiles about $100 \mathrm{~km}$. in length were obtained.

A map shows the structure of the Transdanubian subsoil as determined by geophysical surveys. The writer describes the results of drilling, which were based on the geophysical results, and also summarizes in a table the most important oil-production data for each well.-W. $A$.

\section{NEW PUBLICATIONS}

5963. Chapman, S., and Bartels, J., Geomagnetism, 1:126 pp., 379 illus., Oxford, Clarendon Press, 1940.

Volume 1, Part 1, The observed phenomena of geomagnetism. Chapters: (1) General principles; (2) Magnetic observations; (3) The earth's: main field and its secular variation; (4) Magnetism and geol. ogy-Magnetic prospecting; (5) Solar and lunar data; (6) A general review of the transient magnetic variations; (7) The solar daily variation on quiet days, $S_{q} ;(8)$ The lunar daily magnetic variation; (9) The morphology of magnetic disturbance; (10) Bays, pulsations, and minor disturbances: (11) Magnetic disturbance-Statistics and solar relationships; (12) The 27-day recurrence tendency in mannetic conditions; (13) Earth currents; (14) The aurora polaris; (15) The earth's atmosphere. Volume 2, Part 2, The analysis and synthesis of geomagnetic data. (16) Periodicities and harmonic analysis in geophysics; (17) Spherical harmonic analysis in geophysics; (18) The spherical harmonic analysis of the main field; (19) The variability of the harmonic coefficients for the solar and lunar daily variations; (20) The spherical harmonic analysis of the magnetic variations. Volume 2, Part $\ddot{3}$, Physical theories of geomagnetic phenomena. (21) Theories 
of the main field and its secular variation; (22). Electromagnetic induction within the earth; (23) Theories of the solar and lunar daily magnetic variations, $S_{q}$ and $L ;(24)$ Corpuscular emissions from the sun, and geomagnetic disturbances; (25) Theories of magnetic storms and aurorae; (26) Historical notes. Bibliography.

E. H. Vestine has reviewed this book in detail (see Terres. Magn. and Atmos. Electr., vol. 45, No. 4, pp. 463-470, 1940).-W. A.

3964. Geophysical methods of prospecting in the Arctic [in Russian], Transactions of the Arctic Institute of the Chief Administration of the Northern Sea Route, No. 151, 104 pp., edited by E. E. Fotiadi, Leningrad, 1940. Price, 6 rubles.

This book gives information on geophysical work under Arctic conditions; it discusses specific technical questions arising under the complicated conditions in the Arctic and suggests directions for applying geophysical methods there. It is divided into two parts. The first part gives a general discussion of geophysical work in Nordwik, in the UstPorta region, on the Yugorsk Peninsula, and in the Adicha-Yansk region. The distribution of the stations is shown on a map, and brief information about the work at each station is summarized in a table. In the second part the technique and methods of geophysical work in the Arctic, and the application of gravitational, magnetic, electrical, and seismic methods are discussed. $-W$. A.

5965. Haddock, M. H., Deep borehole surveys and problems, 296 pp., 186 illus., Houston, Tex., Gulf Publishing Co., 1939. Price, $\$ 4$.

This book by Haddock, who is principal of the Mining and Technical Institute, Leicester, England, contains a chapter on geophysical methods of investigating boreholes. It gathers data on all important and accepted means of surveying the courses of deep boreholes.-D. W., Mines Mag., vol. 30, No. 11,1940 .

5966. Jakosky, J. J., Exploration geophysics, 800 pp., 430 illus., Los Angeles, Times-Mirior Press. Price, $\$ 8$.

This volume describes the fundamental theories, equipment, and field techniques of the, recognized exploratory geophysical methods and illustrates their application to problems of economic geology.-W. $A$.

5:67. Lane, A. C., Report of the committee on the measurement of geologic time, 1939-40, 141 pp., Washington, D. C., National Research Council, September 1940.

This report was presented by: A. C. Lane, chairman of the committee, at the annual meeting of the Division of Geology and Geography, National Research Council, April 27, 1940.

.: Contents: (1.) Annotated bibliography of selected articles dealing with the measurement of geologic time, compiled by J. P. Narble; (2) Work of A. O. Nier on the isotopes of lesds; (3) Helium ratio work. This is largely an account of the work at the Massachusetts Institute of Technology; (4) Supplementary general report of the chairman, A. C. Lane; (5) Report on research of summer of 1939, by 0 . B. Muench, with comments by A. C. Lane; (6) Astronomic considerations, by A. C. Lane; (7) Work of B. M. Shaub, outlined by A. C. Lane ; (8) Geotherms, by A. C. Lane; (9) Minor methods of measuring geologic time, by A. O. Lane; (10) Report of the vice chairman, J. P. Marble; (11) Natural 
isotope separations in geology, by J. P. Marble; (12) Translation of recent Russian papers, by J. P. Marble and A. H. Marble; (13) Report from Spain, by J. P. Marble; and (14) Minutes of meetings held during the past year, by A. C. Lane and J. P. Marble.-W. A.

5968. Lynch, Joseph, Our trembling earth, 202 pp., illus., diagrams, New York, Dodd, Mead \& Co., 1940. Price, $\$ 3$.

Contents: (1) Where earthquakes occur; (2) What an earthquake is ; (3) How an earthquake is located and identified; (4) Fordham instruments and New York City vibrations; (5) The value of seismology to the general public; $(6)$ The value of seismology to geology; (7) The value of seismology to the petroleum industry; (8) A description of the Fordham vault; (9) Observatory routine or sighs of a seismologist; (10) World distribution of seismographs; (11) The northeastern group of observatories and local quakes; (12) Seismic core waves; (13) Quakes at a distance of 2,500 miles; (14) Quakes at a distance of 7,000 miles; (15) Quakes at a distance of 10,000 miles; (16) A brief history of earthquakes.

5969. National Research Council, 'Transactions of the American Geophysical Union, Regional meetings, Washington, D. C., 1940.

Part 3-A (pp. 781-830), Symposium with American Association for the Advancement of Science and Geological Society of America, Richmond, Va., December 1938. Contents: Introduction; (1) Relative roles of geology and geophysics in determining crustal structure, by C. R. Longwell ; (2) Mapping of submarine valleys of the Atlantic, by A. C. Veatch and P. A. Smith ; (3) Topography of the former continent of Appalachia (from geological evidence), by W. A. Nelson; ; (4). Present position of the former topographic surface of Appalachia (from seismic evidence), by Maurice Ewing; (5) Gravitational determination of deep-seated crustal structure of continental borders (abservations and methods), by $\mathbf{C} . \mathbf{H}$. Swick; (6) Gravitational determination of deep-seated crustal structure of continental borders (structural interpretation of gravity observations), by G. P. Woollard; (7) The seismic determination of deep-seated crustal structure in California, by Perry Byerly; (8) The time problem in connection with the geophysical study of crustal structure, by $\mathbf{H}$. T. Stetson; (9) Opportunities for collaborative research in further study of continental borders, by W. T. Thom, Jr.

Part 3-B (pp. 831-995), (a) Reports and papers, Western Interstate Snow Survey Conference, Seattle, Wash., June 1940. Contents:---(1) Forecasting, 9 papers; (2) Equîpment, 8 papers; (3) Activitfes, 6 "日apers: (b) Joint meeting of Western Interstate Snow Survey Conference, Section of Hydrology of the American Geophysical Union and American Meteorological Society, 19 papers.

Part 3-C (pp. 996-1061), Joint regional meeting at Seattle, Wash., June 21, 1940, Section of Hydrology, American Geophysical Union, 7 papers.

Part 4-A (pp. 1065-1118). Contents: (1) Preface, by W. D. Cairns; (2) The beginnings of mathematical geophysics in Great Britain, by W. D. Lambert; (3) The use of mathematics in the delineation of magnetic and electric anomalies, by Lachlan Gilchrist and A. R. Clark; (4) Gravimetric and seismic methods in petroleum exploratory geophysics, by M. M. Slotnick; (5) Mathematical problems in seismology, 
by Archie Blake ; (6) A seismologist's difficulties with some mathematical theory or the lack of it, by Perry Byerly.

Part 4-B (pp. 1119-1144). Contents: (1) Preface, by H. A. Meyerhoff; (2) A brief review of ground-water conditions in Michigan, by C. $\mathbf{L}$. McGuinness; (3) Ground-water problems in Ohio, with special reference to the industrial area of Cincinnati, in Butler and Hamilton Counties, by F. H. Daer, Jr.; (4) The hydrologic program of the Weather Bureau, by 'T. S. Southwick; (5) The comprehensive flood-control plan for the Ohio River Basin, by L. A. Pick; (6) Hydrologic aspects of the Muskingum Watershed Conservancy District, by C. C. Chambers; (7) Land use and flood control, by W. F. Simpson and J. S. Cutler.

Parts 3 and 4 both contain indexes of names and subjects. Copies of Transactions may be purchased by nonmembers of the Union as follows: Orders, with check payable to the American Geophysical Union, should be addressed to the General Secretary, American Geophysical Union, 5241 Broad Branch Road, N. W., Washington, D. C., U. S. A. Price, Part 3, $\$ 1.75$; Part $4, \$ 1$.

5970. Washington, H. S., The crust of the earth and its relation to the interior: Geophys. Lab. Carnegie Inst., Washington, D. C., 32 pp., New York, McGraw-Hill Book Co., 1939.

Reprinted from Physics of the Earth VII, Internal Constitution of the Earth, edited by B. Gutenberg, Chapter 5 . Based on the thought that the crust and the interior of the earth are genetically related, studies of the crust will yield information on the interior. To this end the writer treats extensively such topics as the composition of the crust; the basaltic layer; meteorites; earth magnetism; and radioactivity. The numerous subjects and phases covered under such a broad title and the conclusions drawn from them can only be hinted at in a brief abstract. The broad aspects of earth physics treated above have a bearing on exploration geophysics.-D. W., Mines Mag., vol. 30, No, 11, 1940.

\section{PATENTS}

5971. Electrical apparatus and method for locating minerals; William M. Barret, Shreveport, La., assignor to Engineering Research Corporation, Shreveport, La.: U. S. patent 2,201,256, issued May 21, 1940.

In an electromagnetic means for prospecting, an apparatus comprising a generator of electromagnetic waves, said generator being provided with an antenna, a means for maintaining substantially constant energy radiated by said antenna, a meter associated with said antenna whereby said energy radiated by said antenna is indicated, said generator combined with a receiver of electromagnetic waves in a rigid structure, said receiver being provided with a meter the reading of which is proportional to the radio-frequency input to said receiver. Claims allowed, 11.

5972. Method and apparatus for determining the nature of borehole fluids; Alphons Gerard Hubert Straatman, The Hague, Netherlands, assignor to Shell Development Co., San Francisco, Calif., a corporation of Delaware: U. S. patent 2,204,196, issued June 11, 1940.

In a process for determining the nature of a sulstantially electrolytic fluid within a borehole, the steps of lowering thereinto a casing containing a high-frequency oscillatory circuit electrically connected 
with two electrodes carried by said casing in contact with the well fluid, said electrodes being made of materials capable of generating an electromotive force therebetween when immersed in an electrolyte, at least one of said electrodes being insulated from the casing; causing said circuit to generate high-frequency electric oscillations; causing an electromotive force to be generated between said electrodes by contact with the electrolyte; applying said electromotive force to the oscillatory circuit; and determining the nature of the electrolyte well fluid confined between said electrodes from the variations in the electrical characteristics of the oscillatory current due to the changes in the value of the electromotive force generated between said electrodes. Claims allowed, 6.

5973. Means for taking well cores; Charles M. O'Leary, Los Angeles, Calif. : U. S. patent 2,210,464, issued August 6, 1940.

This invention relates to a device for taking side-wall cores, which comprises a core-taking unit including means penetrating the side walls and extracting a core; a well-surveying unit associated therewith for recording the direction and deviation of the well bore from the vertical; an anchor pipe for positioning the structure at a desired depth in a well; means operable through the drill string for actuating the coretaking unit to penetrate the side wall of the well bore and to extract the core; and an electrical circuit operable simultaneously with the core-actuating means for producing operation of the:declination recording device. Claims allowed, 11.

5974. Borehole temperature-measuring device; Helmut Hügel, Campina, Rumania, assignor to Shell Derelopment Co., San Francisco, Calif., a corporation of Delaware: U. S. patent 2,213,802, issued September 3, 1940.

This invention relates to a temperature-measuring device for oil wells comprising a casing; a plunger; a driving mechanism; a rotating member actuated by said mechanism; resilient means adapted to transmit the motion of the rotating member to the plunger; temperatureresponsive means for displacing said plunger transversely to its plane of rotation, said temperature-responsive means comprising a chamber holding a thermally expansible liquid in contact with the lower face of the plunger; packing glands traversed by said plunger and said rotating member within said chamber; a second liquid in said chamber in contact with said glands, said second liquid being immiscible with the first liquid; and means comprising a marker attached to the plunger in contact with the chart to record thereon the compound displacement resulting from said rotational and said transverse motion of the plunger. Claims allowed, 3 .

5975. Geochemical prospecting; Thomas H. Dunn, Tulsa, Okla., assignor to Stanolind Oil \& Gas Co., Tulsa, Okla., a corporation of Delaware: U. S. patent 2,213,904, issued September 3, 1940.

This invention relates to the method of geochemical prospecting, which comprises collecting a plurality of surface soil samples from selected points on the terrain to be surveyed; extracting said samples with an organic solvent having a solvent action on soil waxes; examining the extracts colorimetrically under standardized conditions; and determining the colors of said extracts with relation to a known standard of comparison, 
whereby the relative amounts of soil waxes present in said samples are determined and compared as indices to the presence of underlying hydrocarbon deposits. Claims allowed, 8.

5976. Geochemical prospecting; Joseph Baldwin Clark, Tulsa, Okla., assignor to Stanolind Oil \& Gas Co., Tulsa, Okla., a corporation of Delaware : U. S. patent 2,213,905, issued September $3,1940$.

This invention relates to the method of examining geological formations for subsurface hydrocarbon deposits, which comprises collecting a plurality of geological samples from predetermined spaced sample stations; extracting each of said samples with an organic solvent material having a known refractive index, which is substantially different from the refractive index of the hydrocarbons to be extracted, and having a solvent action on hydrocarbons; and determining the refractive indices of each of the -solutions thus obtained, whereby the variations in refractive index from sample station to sample station resulting from the dissolved hydrocarbons in the extracts may be determined to provide data for evaluation of the presence of subsurface hydrocarbon deposits. Claims allowed, 9.

5977. Method of logging wells; John T. Hayward, Tulsa, Okla.: U. S. patent 2,214,674, issued September 10, 1940.

This invention relates to the method of logging the strata of an oil or gas well while being drilled by the employment of a circulating fluid, comprising: Causing successive portions of the core dilled from a stratum and the respective fluid contents of such core portions to become dilutedly dispersed in successive increments of the drilling fluid column, which is maintained at a head exceeding the head of said stratum; measuring the depth of said stratum in synchronism with the rise of a selected increment from said stratum; identifying said increment at the top of the well as related to the depth of said stratum; and making an analysis of said selected increment at the top of the well, in order to determine the character of the fluid contents of the core portion dispersed in said increment. Claims allowed, 10.

5978. Apparatus for logging holes while drilling; Barton P. Bishop, Houston, Tex.: U. S. patent 2,214,786, issued September 17, 1940.

This invention relates to apparatus for determining the relative character of subsurface geological strata comprising the usual drill; an uninsulated electrical conductor extending from said drill to the surface; a ground electrode; and an instrument responsive to differences in electromotive force connected in a circuit between said conductor and said electrode, said circuit being devoid of any other' source of potential. Claims allowed, 2.

5979. Seismic surveying; John E. Owen, Tulsa, Okla., assignor to Geophysical Research Corporation, New York, N. Y., a corporation of New Jersey : U. S. patent 2,215,297, issued September 17, 1940.

This invention relates to the method of seismic surveying which comprises creating a source of seismic waves at the earth's surface; separately detecting two angularly related components of the resulting earth motion at a point on the earth's surface, said earth motion being the resultant of motions produced by surface waves, by refracted waves, 
and by reflected waves; converting each of said detected earth-motion components into a corresponding electrical wave; adjusting said electrical waves to bring the surface wave components thereof into proper relationship substantially to cancel each other when combined; combining the adjusted electrical waves; and recording the resulting wave form. Claims allowed, 15.

5980. Seismic surveying; John E. Owen, Tulsa, Okla., assignor to Geophysical Research Corporation, New York, N. Y., a corporation of New Jersey : U. S. patent 2,216,452, issued October 1, 1940.

This invention relates to the method of seismic surveying which comprises creating a source of seismic waves at the earth's surface; separately detecting the vertical and horizontal components of the resulting earth motion at a point on the earth's surface, said earth motion being the resultant of motions produced by surface waves, by refracted waves, and by reflected waves; converting each of said detected earth-motion components into a corresponding. electrical wave; adjusting said electrical waves to bring the surface wave components thereof into proper relationship substantially to cancel each other when combined; combining the adjusted electrical waves; and recording the resultant wave form. Claims allowed, 10.

5981. Apparatus for determining the alterations of the horizontal components of the force of gravity; John David Malmquist, Boliden, Sweden, assignor to Bolidens Gruvaktiebolag, Stockholm, Sweden, a joint stock company, limited, of Sweden : U. S. patent 2,217,123, issued October 8, 1940.

This invention relates to an apparatus for determining the extent of ores and the like by determining changes in the horizontal components of the force of gravitation, which comprises in combination two plummets; common means for suspending said plummets a predetermined distance one from the other; means forming variable condensers with each plummet whereby horizontal deflections of the plummets can be measured; said condenser means each comprising a stationary plate and a movable plate which is the plummet itself, whereby the movement of each plummet due to deflections effected by horizontal gravitational force will vary the capacity of each condenser ; and means for measuring the capacity of the condensers to effect a measurement of the angle between the plummets. Claims allowed. 3 .

5982. Gravity measuring instrument; Haakon Muus Evjen and David Saville Muzzey, Jr., Houston, Tex., assignors to Shell Development Co., San Francisco, Calif., a corporation of Delaware: U. S. patent $2,217,361$, issued October 8, 1940.

In a gravity meter, a knife-edge fulcrum, a casing supported thereon, said casing comprising two gas-tight chambers maintained at different pressure, a liquid-filled container in each chamber open to the pressure therein, a conduit between the two containers adapted to permit a liquid flow therebetween upon a change in the value of the gravitational acceleration, the centers of gravity of the liquid in the two containers being offset with regard to a vertical plane passing through the knife edge. Claims allowed, 7. 
5983. Apparatus for solving seismographic problems; John F. Anderson, Beaumont, Tex., assignor to Sun Oil Co., Philadelphia, Pa., a corporation of New Jersey : U. S. patent 2,217,720, issued October 15, 1940.

This invention relates to an apparatus for the solution of problems arising in seismographic prospecting comprising means providing a track ; a pair of slide members movable along the track; means for maintaining said slide members in fixed relation to each other during such movements ; an arm pivoted to each of said slide members and adapted to extend over a surface to which said track is parallel; and means adjustably pivotally joining said arms in converging relationship. Claims allowed, 4.

5984. Apparatus for orienting cores; John M. Pearson, Swarthmore, Pa., assignor to Sperry-Sun Well Surveying Co., Philadelphia, Pa., a corporation of Delaware: U. S. patent 2,217,768, issued October 15, 1940.

In combination a suspended magnetic system, means for mounting a core from a borehole for rotation about an axis perpendicular to the axis of suspension of said system, means for providing a photographic record of deflections of said system, means for rotating in both directions a core so mounted, and means for distinguishing records of deflections produced during rotation of a core in one direction from those produced during rotation of the core in the opposite direction. Claims allowed, 7 .

5985. Method of electrical-geophysical prospecting and apparatus for practicing said method ; Thomas S. West and Clarence C. Beacham, Lockhart, Tex. : U. S. patent 2,217,780, issued October 15, 1940.

This method relates to the method of vertical electrical exploration below spaced-apart current electrodes employed for creating a distribution of electric current in the earth, which comprises creating at different times two of said distributions of electric current in the earth between each of a plurality of pairs of spaced-apart grounded potential electrodes located at different distances from at least one of said current electrodes, and then for the same position of said potential electrodes making simultaneous measurement of the potential difference caused to exist between each pair of said potential electrodes by the other of the said two distributions of electric current in the earth. Claims allowed, 16.

5986. Seismograph prospecting; Gary Muffly, Oakmont, Pa., assignor to Gulf Research \& Development Co., Pittsburgh, Pa., a corporation of Delaware: U. S. patent 2,217,806, issued October 15, 1940.

In seismograph apparatus having an electrical seismophone arranged to produce signals of various frequencies corresponding to terrestrial vibrations and varying with time, some of which signal frequencies it is desired to record, the combination of an electronic amplifier circuit connected therewith and a recorder connected with the amplifier circuit; variable tuning means for the amplifier circuit; and timer means operating independently of fluctuations in signal amplitude and constructed and arranged to adjust the tuning means as a predetermined function of elapsed time during receipt of the signals, such as to maintain the amplifier tuned for receipt of the desired signals. Claims allowed, 12.

5987. Seismograph prospecting apparatus; Ralph D. Wyckoff, Houston, Tex., assignor to Gulf Research \& Development Co., Pittsburgh, Pa., a corporation of Delaware: U. S. patent 2,217,828, issued October 15, 1940.

In combination with a recorder, a vacuum-tube circuit for amplifying seismophone signals of varying frequencies; means for supplying elec- 
trical energy of a chosen frequency to the circuit; means for modulating: said frequency according to the variations in said seismophone signals, thereby producing frequency side bands; means for selecting some of the frequencies in one of said side bands; detecting and recording means in connection with said frequency selecting means; and means for adjusting chosen frequency whereby to control the frequency response of the circuit. Claims allowed, 4.

5988. Gravity torsion balance; Frederick E. Wright and Joseph L. England, Washington, D. C., assignors to Carnegie Institution of Washington, Washington, D. C.; a corporation of the United States: U. S. patent 2,218,140, issued October 15, 1940.

In a torsion gravity balance, the combination with a horizontally ar. ranged helix of elastic material; a frame carrying the helix; means including a hollow shaft supporting said frame for rotation about the axis of the helix; a boom extending radially from the center of the helix; means for indicating the angular rotation of the frame, which displaces the boom into horizontal positions at opposite sides of the helix; and means for supporting the helix when the apparatus is not in use, said supporting means comprising elongated pans piroted to the ends of the frame and positioned beneath the helix, a linkage system for raising and lowering each pan, and operating means for said linkage systems extending into said hollow shaft. Claims allowed, 9.

5989. Well logging by measurements of radioactivity; Serge Alexander Scherbatskoy, Tulsa, Okla., assignor to Well Surveys, Inc., Tulsa, Okla., a corporation of Delaware: U. S. patent 2,219,273, issued October 22, 1940.

This invention relates to a method of obtaining geophysical data that comprises impressing a constant potential across spaced electrodes in an atmosphere of inert gas under superatmospheric pressure; continuously lowering said electrodes into an opening in the earth; obtaining from the electrode circuit a substantially continuous electrical output current, the voltage of which corresponds to the current flow in the electrode circuit altered by radiation from surrounding strata; converting said output current to a pulsating signal; amplifying said signal ; continuously recording this amplified signal; continuously measuring the depth at which the electrodes are positioned in the earth; and continuously recording said measurements in correlation with the record of said current. Claims allowed, 13.

5990. Well survey method and apparatus; Serge Alexander Scherbatskoy, Tulsa, Okla., assignor to Well Surveys, Inc., Tulsa, Okla., a corporation of Delaware: U. S. patent 2,219,274, issued October 22, 1940.

This invention relates to a method of geophysical exploration that comprises lowering an ionization chamber into a drill hole or the like and measuring the rate of current flow therethrough at various levels as an indication of the intensity of the radioactive radiations encountered at those levels, the method of measuring the rate of flow of the current through the ionization chamber that comprises electrically matching said current flow with an external current flow ; transmitting an indication of any difference between said current to a recording point; adjusting said external current flow at said recording point so that it will exactly balance the current flow through the ionization chamber by ref- 
erence to the transmitted indication of difference; and recording the magnitude of the external current flow as a measure of the intensity of the radiations impinging upon the ionization chamber. Claims allowed, 11.

5991. Method and apparatus for seismic surveying; Lawrence F. Athy and Elton V. McCollum, Ponca City, Okla., assignors to Continental Oil Co., Ponca City, Okla., a corporation of Delaware: U. S. patent 2,219,508, issued October 29, 1940.

This invention relates to an apparatus for reflection seismic surveying comprising means for generating seismic waves, a large number of seismometers arranged in line with each other, said line being horizontally offset from the position of said generating means by a distance of from about $75 \mathrm{ft}$. to about 1,000 ft., and extending in each of two directions from a point opposite said generating means, the end seismometers being substantially equidistant from said generating means, and means responsive to the reflected seismic waves received by the various seismometers for forming a record comprising a plurality of traces. Claims allowed, 14.

5992. Electrical-exporation method; Shell Development Co., San Francisco, Calif., assignee of David Saville Muzzey, Jr., Houston, Tex., both in the United States of America: Canadian patent 389,917, issued July 9, 1940.

This invention relates to a method for electrical exploration of ground strata having different electrolytic properties, the steps of passing through the ground an alternating current, allowing said alternating current to be partially rectified at surfaces of discontinuity between said strata, and observing the direct-current potential difference generated in the ground by said rectification. Claims allowed, 4 . 



\section{INDEX}

[The figure in parentheses refers to the class in which the entry stands; see list in table of contents]

\begin{tabular}{|c|c|c|c|}
\hline \multicolumn{2}{|c|}{ Abstract } & \multicolumn{2}{|c|}{ Abstract } \\
\hline belski, M. E. & 5877 & Gulf Research \& Development Co. & \\
\hline Adkins, J. N. (3) & 5910 & 5986 & 5987 \\
\hline Aliverti, Gluseppina (5) & 5949 & Gurevich, B. L. (4) & 5941 \\
\hline Anderson, J. F. (10) & 5983 & & \\
\hline Irctic. Institute $(9)$ & 5964 & Haddock, M. H. (9) & 5965 \\
\hline Athy, L. F. (10) & 5991 & $\begin{array}{l}\text { Hafner, W. (3) } \\
\text { Hagiwara, Taliahiro }(3)\end{array}$ & $\begin{array}{l}5917 \\
5919\end{array}$ \\
\hline Baird, H. F. (3) & 5911 & Hallimond, A. F. (2) & 5895 \\
\hline Ballarin, S. (1) & 5878 & Harland, W. B. (3) & 913 \\
\hline Bancroft, Dennison (3) & 5912 & Hattori, Yasumasa (3) & 924 \\
\hline Banwell, C. J. (3) & 5911. & Hayakawa, Masami (3) & 5924 \\
\hline Barret, W. M. (10) & 5971 & Hayward, J. T. (4) & 5942 \\
\hline , J. (9) & 5963 & $-(10)$ & 5977 \\
\hline $\mathrm{m}, \mathrm{C} . \mathrm{C} .(10)$ & 5985 & Hendricks, T. A. (1) & 5881 \\
\hline N. P. (2) & 5891 & G. (1) & 5882 \\
\hline ncis (3) & 5912 & i. $(5)$ & 5950 \\
\hline P. $(10)$ & 5978 & $\lg (8)$ & 5959 \\
\hline W. (8) & 5956 & ut $(10)$ & 5974 \\
\hline Uruvaktiebolag $(10)$ & 5981 & & \\
\hline Rudolf (4) & 5937 & Ising, $\mathrm{Gu}$ & 5883 \\
\hline E. C. $(3)$ & 5913 & & \\
\hline A. J. $(2)$ & 5895 & $\begin{array}{l}\text { sky, J. J. (9) } \\
\text { s, W. M. (2) }\end{array}$ & $\begin{array}{l}5966 \\
5896\end{array}$ \\
\hline $\begin{array}{l}\text { Carder, D. S. (3) } \\
\text { Carnegie Institution of Washington }\end{array}$ & 5914 & Jordan, W. H. (2) & 5897 \\
\hline - & 5988 & Kan & 5920 \\
\hline Chapman, S. (2) & 5893 & Kanai Kiyoshi (3) & 5931. \\
\hline$(9)-10-0$ & 5963 & $(6)$ & 5954 \\
\hline B. $(10)$ & 5976 & Kaneko, Tetuiti (3) & 5924 \\
\hline tal Oil Co. $(10)$ & 5991 & Kato, Yosio (2) & 5899 \\
\hline Culbertson, J. A. (4) & 5938 & $\begin{array}{l}\text { Kedves, M. (1) } \\
\text { Kerr-Grant, C. (3) }\end{array}$ & $\begin{array}{l}5984 \\
5913\end{array}$ \\
\hline------- & 5975 & Kornfeld, J. A. (8) $\ldots \ldots \ldots$, & 5961 \\
\hline A. $(8)$ & 5957 & 9) & 5967 \\
\hline ering Research Corporation & & L. D. (3) & 5921 \\
\hline on & 5971 & a, G. (5) & 5949 \\
\hline J. L. $(10)$ & $5988^{\prime}$ & vchenko, P: I. (f) & 5885 \\
\hline M. $(10)$ & 5982 & $(2)$ & 5900 \\
\hline Iaurice $(3)$ & 5915 & $\begin{array}{l}\text { Lynch, Joseph (3) } \\
\end{array}$ & $\begin{array}{l}5922 \\
5968\end{array}$ \\
\hline A. (2) & 5894 & A. (3) & 5923 \\
\hline o. (3) & 5916 & Lynton, E. D. (2) & 5901 \\
\hline Volker $(4)$ & 5940 & & \\
\hline Frost, V. L. (8) & 5958 & $\begin{array}{l}\text { J. D. }(10) \\
\text { C. M. (2) }\end{array}$ & $\begin{array}{l}5981 \\
5902\end{array}$ \\
\hline 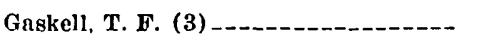 & 5913 & Oscar (4) & 5943 \\
\hline $\begin{array}{l}\text { Geophysical Research Corporation } \\
\text { (10) }\end{array}$ & & $\begin{array}{l}\text { Takeo }(3) \\
\text { E. V. }(10)\end{array}$ & $\begin{array}{l}5924 \\
5991\end{array}$ \\
\hline erhard $(1)$ & 5879 & J. (3) & 5925 \\
\hline (1) & $\mathbf{5 8 8 0}$ & P. L. (4) & 5944 \\
\hline
\end{tabular}


Miller, A. H. (1)

Millikan, C. V. (6)

Milstein, M. (2)

Minakami, Takesi (2)

Miyamura, Setumi (3)

Muffly, Gary (10)

Muzzey, D. S., Jr. (10) 5986 5982,5992

Nagata, Takesi :(2)

National Research Council $(9)$

Nature (editorial) (3)

5905

5969

5927

Ogilvi, A. A. (4)

O'Leary, C. M. (10)

Olesen, Raymond (3.)

5945

5973

Omote, Syunitiro (3)

5933

Owen, J. E. (10)

$--$

5919

Pearson, J. M. (10)

Pospelov, P. A. (3)

5984

Regula, Walter (3)

Ricker, Norman (3)

Ruark, A. (2)

Russell, W. L. (5)

5)

Sajina, N. B. (1)

Scherbatakoy, S. A. (1

\section{Scherbatskoy, S. A. (10)}

Schulte, Fr. (4)

Sezawa, Katsutada (3) (6)

Shaskolski, v. V. (4)
Shell Development Co. (10) $\begin{array}{r}\text { Abstract } \\ -\quad 5972,\end{array}$ $5974,5982,5992$

Shirkie, J. T. (2) 5906

Slichter, L. B. (6) _. 5955

Sperry-Sun Well Surveying Co. (10) 5984

Stanolind Oil \& Gas Co. (10) _... 5975, 5976

Straatman, A. G. H. (10)

Strona, A. A. (2)

Sun:Oll Co. (10):_na 5983

Swanson, C. O. (2) _.. 5908

Toperczer, Max (3)

Vine, A. C. (3)

Voit, H. (1) 5888

von Zwerger,'Rudolf (.8)

Washburn, Harold (3)

Washington, H. S. (9) _._._._._ 5970

Webb, E. R. (2)

Wegener, Kurt (1) _._._.______ 5889

Well Surveys, Inc. (10) ______ 5989,5990

West, T. S. (10) _.

Wolf, Alfred (1)

W (3)

Wölk, Ernst (4)

Woollard, G. P. (3)

Wright, F. E. (10) _... $598 \mathrm{~s}$

Wyckoff, R. D. (10)

Zagarmistr, A. M. (4)

Zirbel, N. N. (3) 